\title{
Sequential vertical gas charge into multilayered sequences controlled by central conduits
}

\author{
M. Foschi ${ }^{1 *}$, J.A. Cartwright ${ }^{1}$, and C.W. MacMinn ${ }^{2}$ \\ ${ }^{1}$ Shell Geoscience Laboratory, Department of Earth Sciences, University of Oxford, \\ Oxford, UK \\ ${ }^{2}$ Department of Engineering Science, University of Oxford, Oxford, UK \\ *(corresponding author), email: martinof@earth.ox.ac.uk
}

\section{Acknowledgments}

We thank Royal-Dutch Shell for sponsoring this project under the Shell-Oxford Research Collaboration. We are very thankful with Toegepast Natuurwetenschappelijk Onderzoek (TNO), Geological Survey of the Netherlands, for academic access to seismic and well data. We are grateful to Schlumberger, CGG (Hampson-Russell Software), and The Mathworks for providing software support. We thank Luke Jenkins, Pieter Van Rensbergen and Bruce Levell for their constructive comments on an earlier version of this manuscript. We also thank Mike Daly, Sean McQuaid and David Griffiths for their help with well data and calibration. The constructive reviews of Katrine Juul Andresen and Ilya Ostanin also helped to improve the manuscript significantly.

\section{Abstract}

Four sets of stacked amplitude anomalies are described from a 3D seismic survey acquired in Block A of the Dutch North Sea. The amplitude anomalies have a sub-circular planform and within each set they are stacked vertically, in that they have a high degree of spatial overlap in the vertical succession. These sets of amplitude anomalies are interpreted as vertical anomaly clusters composed of 5-7 major amplitude anomalies each. Seismic interpretation of the vertical anomaly clusters and quantitative analysis of the reservoir intervals reveal that the vertical anomaly clusters are gas-bearing silt-rich reservoirs hosted in the upper section of the Upper 
North Sea Group, a mixed clastic succession of Pliocene to Pleistocene age. Novel analysis based on the geometry of the individual anomalies reveals that these are likely to be the result of a gas migration process characterised by sequential upward gas charge into reservoir units and that the flow across the seals separating these reservoirs is controlled by central regions of focussed fluid flow. These regions function as seal-by pass systems and are most likely formed by hydraulic fracturing.

\section{INTRODUCTION}

Vertical hydrocarbon migration is an integral component of many petroleum systems (England et al., 1987; Demaison and Huisinga, 1991). This complex process can include insolution transport mechanisms (Cramer et al, 2002), such as diffusion and convection, but is generally believed to be dominated by buoyancy-driven migration of free-phase hydrocarbons (Bonham, 1980; Etiope and Martinelli, 2002; Løseth et al., 2009; McAuliffe, 1979; Roberts and Cordell, 1980; Schowalter, 1979). The vertical migration of hydrocarbons is often observed in petroleum systems where the source and the kitchen are several thousand metres distant. The intervening sealing sequences, acting as barrier to vertical hydrocarbon migration, have led to the useful conceptual term of "high impedance vertical drainage" (Demaison and Huisinga, 1991). This term, when referred to a specific basin, capture the high impedance to the migration process.

Despite many decades of research, there are significant uncertainties in our understanding of vertical migration mechanisms, although free-phase hydrocarbon migration through the pore network and fracture networks (pre-existing or fluid-induced) is tacitly assumed to dominate depending on the magnitude of the buoyancy force of the hydrocarbon column (Jain and Juanes, 2009; Liu and Flemings, 2007). Nevertheless, progress has been made in recent years by interpreting hydrocarbon migration routes using 3D seismic data, to define hydrocarbon 
plumbing systems on a sub-basinal scale (see Andresen, 2012 for review). The high spatial resolution of 3D seismic data allows to detect in detail the hydrocarbon occurrences, often called direct hydrocarbon indicators, or DHIs (see Brown 1996). These are subsequently used to identify potential linkages and define migration routes (Cartwright et al. 2007; Foschi and Cartwright, 2016; Løseth et al. 2009).

A recent example of this approach and its application to the question of the mechanism of vertical transport was presented by Foschi et al (2014). They used a closely spaced grid of 2D reflection profiles from the eastern margin of the Falkland Islands to identify vertical migration pathways for thermogenic gas from a deep kitchen into the shallow overburden across low permeability, hemipelagic successions more than $3 \mathrm{~km}(9842 \mathrm{ft})$ thick (high-impedance drainage end-member of Demaison and Huisinga, 1991). The seismic expression of this migration process on the 2D seismic data was a series of vertically stacked amplitude anomalies (AAs) producing a well-defined and localised region of acoustic amplification (due to gaswater substitution). The authors suggested that these stacked AAs were linked by vertical migration of gas through a fault and fracture network and introduced a new term to the catalogue of DHIs: the vertical anomaly cluster (VAC). Although the study was able to define the general characteristics of more than 50 VACs in the basin, the precise shapes of the AAs and their relationship to the structure and lithology of the host sediments could not be established because of the limited spatial resolution of the 2D seismic grid and the lack of well calibration.

In this study, we build on the work of Foschi et al (2014) by presenting a study, calibrated by well data, of a group of VACs located in the Dutch Sector of the Southern North Sea. One the VACs here described, VAC-2, is a commercially producing gas field, A12-FA (described later). The VACs are composed by individual AAs, which exhibit a lateral extent of over several kilometres and stack vertically for 300-400 m (980-1312 ft). The VACs are here hosted 
in an interval consisting of a thinly (5-15 $\mathrm{m}$ [15-50 ft]) interbedded series of fine silts and clays of dominantly shelfal and deltaic origin.

The availability of high quality 3D seismic data tied to three exploration boreholes complete with core calibrations of the main interval of interest (the interval hosting the VACs) provided an opportunity to document and analyse in an integrated approach migration pathways and hydrocarbon plumbing system. The gross stratigraphy and permeability structure of the interval hosting the VACs, which tends to the low-impedance vertical-drainage system of Demaison and Huizinga (1991), provides a useful contrast to the finer-grained deepwater hemipelagite facies that hosted the VACs described from the East Falkland Basin by Foschi et al (2014).

The 3D seismic, in particular, allowed us to define the margins of the constituent AAs comprising the VACs in the study area, and from the detailed mapping of these anomalies derive a methodology for inferring the main focus of vertical migration. The main aims of this study therefore are: (1) to provide a rigorous description of the stacked AAs, (2) to analyse the mechanisms contributing to their formation and their sub-regional distribution in the context of the local petroleum systems, and (3) to explore the wider significance of these features as clues to the detailed mechanisms involved in vertical hydrocarbon migration.

\section{DATA AND METHODS}

\subsection{Data}

The study is based on a combination of post-stack high-resolution 3D seismic data and welllog data provided by Toegepast Natuurwetenschappelijk Onderzoek (TNO) and located in Block A of the offshore Dutch sector, Southern North Sea (Figure 1). The 3D seismic data was acquired and processed in 2000 by Fugro-Geoteam AS and covers an area of approximately $610 \mathrm{~km}^{2}\left(380 \mathrm{mi}^{2}\right)(26.12 \times 23.36 \mathrm{~km}[16 \times 14 \mathrm{mi}])$, with a cross-line and in-line spacing of 

AS using a standard sequence for marine seismic data, and using predictive deconvolution to attenuate the water-bottom multiples (Yilmaz, 1999). The data was completed with a zerophase wavelet with American polarity ( $\mathrm{RC}+$ peak). The vertical resolution is calculated as a quarter of the dominant wavelength (Widess, 1973) and ranges from $7 \mathrm{~m}(22 \mathrm{ft})$ in the shallow interval (0-1 s TWT i.e. the main interval of interest) to $22 \mathrm{~m} \mathrm{(72} \mathrm{ft)} \mathrm{at} \mathrm{depth} \mathrm{(1-4} \mathrm{s} \mathrm{TWT).}$ Horizontal resolution is approximately equal to the vertical one (Brown, 1996). Tuning thickness is approximately $14 \mathrm{~ms}$ TWT (half of the dominant wavelength).

The well data used in this study derives from three boreholes, A15-02, -03 and -04 (Figure 1). The well data is located within the area covered by the 3D seismic volume. This well data comprises a combination of wireline logs, including sonic, gamma-ray, neutron porosity, resistivity, and core data. The core data was not directly available for this study however, a large number of petrophysical and sedimentological reports based on these boreholes was provided.

\subsection{Methods}

Data interpretation and manipulation following previously published seismo-stratigraphic frameworks completed within the same 3D seismic data (e.g. Kuhlmann and Wong, 2008, Stuart and Huuse, 2012). The interpretation allowed us to define 15 seismically correlatable packages based on internal reflection architecture and seismic facies (Mitchum et al., 1977). Thirteen seismic-stratigraphic sequences (S1 to $\mathrm{S} 13$ ) used in this study are consistent with the previously defined sequence framework completed by Kuhlmann and Wong (2008). Two additional sequences S14 and S15 
were introduced here in order to subdivide the shallower section of the Upper North Sea Group. This subdivision was based on the interpretation of one extra horizon separating the two packages based on internal seismic facies rather than a purely sequence-stratigraphic approach (Posamentier and Allen, 1999).

The interpreted horizons were used to calculate surfaces by using convergent interpolation methods and $25 \times 25 \mathrm{~m}(82 \times 82 \mathrm{ft})$ grid spacing. The surfaces were converted from time to depth using the time-to-depth parameters obtained from the well-to-seismic calibration (described later). Amplitude maps were calculated by extracting the values along one of the wave-loop of the interpreted horizon (e.g. negative loop for the AAs). This simple amplitude extraction was preferred because it preserves the original polarity of the horizon and avoids summations of positive and negative values (e.g. RMS amplitude maps are positive only).

The interpreted packages were tied with wells A15-02, -03, -04, using Hampson-Russell Software (HRS) provided by CGG. The tie involved the generation of synthetic seismograms derived from velocity and density log from each well. The logs were first edited applying manual and automated de-spiking operations. Manual editing was applied to those logs characterised by anomalous values. The logs were then up-scaled using a variable blocking operator. The Backus averaging blocking method (Backus, 1962) was used for this operation and was based on the entire composite log data for each well. The generation of synthetic seismograms was completed applying statistical wavelets obtained from the 3D seismic data. The obtained wavelet was zero-phase and nearly consistent with a Ricker wavelet in shape.

The synthetic seismograms were finally calibrated to the 3D seismic data by using checkshot tables and then by applying manual stretching and shifting adjustments. These steps were monitored following the cross-correlation response between the synthetic seismogram and the trace(s) extracted at the well path. 
A simplified geological model, based on the shale content of the interval of interest, was based on gamma-ray well-log data calibrated with the cuttings and $\mathrm{x}$-ray diffraction (XRD) analysis conducted by PANterra Geoconsulting BV. This methodology was used instead of more effective techniques (e.g. Lambda-Mu-Rho; Goodway et al., 1997) because of the lack of shear velocity data. The gamma-ray log was used to compute the volume fraction of shale, $V_{S H}$, based on the empirical relation (e.g. Miller and Stewart, 1990)

(1)

$$
I_{G R}=\frac{G R_{\text {log }}-G R_{\text {clean }}}{G R_{\text {shale }}-G R_{\text {clean }}}
$$

where $I_{G R}$ is the gamma-ray index, $G R_{l o g}$ the measured gamma-ray, $G R_{c l e a n}$ the minimum gamma-ray (outside casings) and $G R_{\text {shale }}$ the largest value of the readings. The $V_{S H}$ was obtained using the Larionov (1969) empirical relation for Cenozoic rocks, $V_{S H}=0.083 \times\left(2^{3.7 \times I}{ }_{G R}-1\right)$. The results were then compared with the interpretation of the lithology from cuttings and calibrated with the clay fraction calculated from XRD analysis. After the calibration three $\mathrm{V}_{\mathrm{SH}}$ threshold values were selected to subdivide the sedimentary column into reservoir and seal layers, reflecting upper mid and lower threshold cases.

$$
\text { Identification of potential gas-charged layers from log data was derived by scaling the }
$$
density log to porosity based on a sandstone scale method (Edmundson and Raymer, 1979). The neutron porosity log and the porosity derived from density log were then crossplotted using identical porosity axes limits. Potential gas-charged layers were identified from the crossover of the two curves (Helander, 1983). In the following description, we refer to these potential regions of gas accumulation as gas-crossovers (Helander, 1983). 
The AAs were mapped using standard manual and auto-track interpretation tools present in Schlumberger's Petrel software. The amplitude maps were made by extracting the peak value of the amplitude sampled along the interpreted horizons. Geometrical analysis of the anomalies was made by extracting the lateral margins of the anomalies using amplitude maps. The position in $\mathrm{x}, \mathrm{y}$ coordinates of the lateral margin was used as an input to calculate the centroids. The extraction of the margins was carried out by defining an amplitude cut-off. This unbiased method was preferred for repeatability. The coordinate of the centroid $C_{x, y}$, here intended as equation,

189

$$
C_{x, y}=\frac{\sum_{i=1}^{n} x_{i}}{n}, \frac{\sum_{i=1}^{n} y_{i}}{n}
$$
reasonable approximation.

where $x_{i}$ and $y_{i}$ are coordinates of the $n$ element belonging to the area enclosed within the margin of the anomaly (Bird, 2014). This equation assumes that the AAs are horizontal $(\Delta \mathrm{z}=$ $0)$. Because of the limited vertical extent of each AAs the equation here used represent a

\section{GEOLOGICAL SETTING}

\subsection{Regional geological evolution}

The study area is located within Blocks A and B of the Dutch Sector of the North Sea, on the western flank of the Dutch Central Graben (Figure 1). This region forms part of the central North Sea Basin, bordering the Mid North Sea High to the west. It lies near the northern margin of the Southern Permian Basin, and the older stratigraphy of the area thus consists of thick, halokinetically deformed Zechstein evaporites overlying a Carboniferous succession that is known to contain organically enriched intervals, and that along with the classic coal measures 
successions are a source for gas in most of the Southern Gas Province of the North Sea Basin

206 (Doornenbal and Stevenson, 2010). The present-day maturation of these source rocks, represented mainly by Pre Zechstein rocks (e.g. Dinantian and Namurian, which are shallow marine deltaic Type III source rocks) and expressed here as vitrinite reflectance, is of the order of $1-2 \%$ (Gerling et al., 1999).

210 A phase of regional subsidence in the Late Permian was followed by rifting causing the formation of the main graben systems in the Triassic and Late Jurassic (Kimmeridgian phase), such that the deeper Mesozoic section of this part of the basin is dominated by the main rift axes and basement normal faults that were locally oriented N-S (Figure 1B). The Late Jurassic rift phase was followed by thermal, post-rift subsidence on a regional scale from the Early Cretaceous to the present day (Evans et al., 2003). Regional subsidence was punctuated by inversion tectonics at different times, with pronounced phases of regional or local uplift and erosion in the Mid Cretaceous, Late Cretaceous and Early Cenozoic (Ziegler, 1990). Chalk deposition in relatively deepwater environments in the Late Cretaceous was followed by a gross shallowing upwards succession during the Cenozoic, dominated by low permeability claystones in the Paleogene and early Neogene (Stuart and Huuse, 2012). Increasingly coarser input into the shallower water of the waning regional sag basin resulted from reorganisation of the marginal fluvial systems, with a significant deltaic input derived from the uplifted Fennoscandian Shield from the late Oligocene on into the Pleistocene (Overeem et al, 2001). Major glacial advances occurred in the Pleistocene, and resulted in a more complex stratigraphy with large channel-like features (tunnel valleys) being cut into flat-lying interglacial sequences consisting largely of clays and silts (Stuart and Huuse, 2012). 
A12-FA is a multiple-reservoir gas field operated by Chevron since 2007. The vertically stacked reservoirs (six) are located at a depth interval of 300-600 m (980-1970 ft) below the seabed and are partially imaged by the 3D seismic volume used in this study (A12-FA will be referred to as VAC-2 in the following descriptions). The reservoirs are composed of unconsolidated shallow marine and deltaic sands of Plio-Pleistocene age (ten Veen et al., 2014). The seal units are composed of siliciclastic intra-delta argillaceous clay. The reservoir and seal intervals hosting A12-FA gas field is equivalent to the lithology hosting the other VACs encountered in this study (described later).

\subsection{Detailed Stratigraphy of the Upper North Sea Group}

The main interval of interest for this study is the Upper North Sea Group. This clastic succession was dominated by depositional systems linked to the Eridanos Delta, a fluviodeltaic depositional system (Overeem et al. 2001) whose transport direction was predominantly westerly towards the basin axis close to the study area from entry points on the eastern margin of the Southern North Sea Basin. This produced a consistently westward progradation of the delta fronts until the complete filling of the basin occurred in the Pleistocene (Figure 2).

The Upper North Sea Group has been subdivided by a number of previous studies based on seismic-stratigraphic and log characteristics (Sørensen et al, 1997; Overeem et al, 2001; Kuhlmann et al., 2004; Kuhlmann and Wong, 2008). We follow this stratigraphic subdivision here with the minor addition of two seismic-stratigraphic units to encompass the shallowest, Late Pleistocene to Holocene interval (Figure 3). Accordingly, in the study area, 15 different sequences are identified and correlated to the wells using the seismic data (S1 to S15). The correlation with well and petrophysical data allowed also to identify potential reservoir and seal layers. From the reflection configurations observed in the study area, however, it is clear that there are several groups of these sequences that form discrete packages marked by their 
similarity in gross configuration, and we follow Stuart and Huuse (2012) in the package grouping used to provide a framework for the description below.

Unit 1: Sequences S1-S4

Sequences S1-S4 are bounded at their base by a laterally continuous high amplitude

reflection representing the local expression of the Middle Miocene Unconformity (MMU;

Figure 3A). Their gross thickness varies from c. 400 to c. $300 \mathrm{~m}$ (1300 to $980 \mathrm{ft}$ ) east to west across the study area, reflecting the gross thinning to the western margin of the main depocentre, just east of the study area above the Mesozoic rift system (Figures 1, 2).

The seismic facies of Unit 1 is low amplitude, but with some discontinuity and "V" and "U" shaped reflection truncations. The discontinuities are associated with pervasively developed polygonal faults that deform S1 and S2 (PFS, Figure 3, inset).

Well A15-03 calibrates this interval and shows it to be composed of silty-claystones within

$\mathrm{S} 4$, which is expressed as a relatively low gamma-ray response, and mostly claystones within

S1-S3 (Figure 4A-B). The silty-claystones embedded in S4 are consistent with potential reservoir-like layers, based on shale volume fraction derived from gamma-ray (Figure 4B). The presence of glauconite within S1 implies a typically slow sedimentation process potentially associated with bio-chemical reduction (Triplehorn, 1965). This may suggest the decay of organic matter. Unit 1 is dated as Middle Miocene to Late Pliocene in age (Kuhlmann et al., 2004).

Unit 2: Sequences S5-S7

Sequences S5 and S6 are characterised by a parallel-stratified, low amplitudes seismic facies. The thickness of this unit ranges from 300 to $350 \mathrm{~m}$ (from 980 to $1150 \mathrm{ft}$ ). S5 and S6 thin westward while S7 is thinner to the east, reflecting the advance of the shelf break to the 
west. The acoustic response of this sequence package is similar to that observed for Sequences

S1-S4 (Figure 3). Two major high amplitude discontinuous reflections can be clearly observed toward the top of Sequence S5 and at the sequence boundary between S5 and S6. These reflections, characterised by a soft amplitude response, have been previously described by Stuart and Huuse (2012) and interpreted as contourite sand bodies deposited at water depth of $<300 \mathrm{~m}(<980 \mathrm{ft})$ and associated with a N-S counter clockwise water circulation. At the top of Sequence S7 some bright amplitude reflections, characterised by soft polarity are observed (described later). amplitude progradational reflections building onward into moderate water depths $(<200 \mathrm{~m}$ $[<650 \mathrm{ft}]$ ) to the west (Figure 5). Reflection truncation are also observed at the top of Sequence S7 suggesting at least two cycles of regression. These erosional surfaces are most likely associated with periods of deltaic advance triggered by the cooler environment (Kuhlmann et al., 2004, 2006a).

Sequences S5-7 have been drilled by the wells A15-03 and -04 and were calibrated using cuttings and core data (A15-03 and -04). The prominent bright intermittent reflections embedded within Sequences S5 and S6 are associated with fine-grained sandy-silt, siltstone and show reservoir potential assuming a shale fraction threshold of 38\% (Figure 4B). These intervals exhibit low gamma ray responses with values of nearly 90 API in all the three locations penetrated by the wells (Figure 4A). These intervals also show relatively high permeability ranging from 10 to $100 \mathrm{mD}$, as observed at core 11 of well A15-03 (Figure 4B). Additional petrophysical analyses carried out the operator working in the adjacent gas field (beneath VAC2) and at a depth range of 871-912 m (S6 [2857 - $2992 \mathrm{ft}]$ ) shows the presence of tight lithologies characterised by permeability of $0.38 \mathrm{mD}$ and pore throat radii of $<0.1 \mu \mathrm{m}$. Unit 2 is dated as Gelasian in age (e.g. Stuart and Huuse, 2012). 
Sequences S5-S7 represent the stratigraphic interval where biogenic gas generation was most prolific according to recently published results (e.g. ten Veen et al., 2014). The onset of gas generation started in the Pleistocene and is still active nowadays but does not involve the younger deposits (S8-S15). A depth of nearly $840 \mathrm{~m}(2755 \mathrm{ft})(\mathrm{S} 5)$ has been suggested to represent the top of the biogenic gas generation window (Verweij et al., 2013).

\section{Unit 3: Sequences S8-S12}

Sequences S8-S12 are characterised by a crudely parallel gross geometry with progradational configurations at a regional scale (Figure 2), suggesting water depths of c. 100-

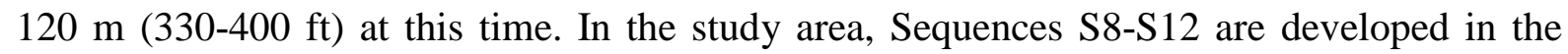
topsets of the Eridanos Delta and hence comprise laterally continuous reflections with locally variable amplitude (Figure 3). Unit 3 exhibits a thickness of nearly $230 \mathrm{~m}$ (754 ft). A number of prominent AAs can be observed in Unit 3 (described later). Unit 3 and sequence S14 of Unit 4 will be also referred to as the anomaly interval (AI) in the next sections.

A system of linear features is recognisable within Unit 3 (Figure 5, 6E and 8D). With reference to representative amplitude and chaos maps, calculated along the sequence boundary between S9 and S10 (Figure 5) and S10 and S11 (Figure 6E and 8D), these linear features are typically a few tens of metres wide, up to several kilometres long and are mostly oriented NS. They have been interpreted as iceberg ploughmarks by Kuhlmann and Wong (2008) and Stuart and Huuse (2012) and mark the transition to arctic climatic conditions in this interval (Kuhlmann and Wong, 2008), which is dated as late Gelasian to early Calabrian in age.

The presence of prominent AAs, which will be described later, produces a significant enhancement of the continuity of the horizons within this unit, relative to their original seismic facies. Extensive mapping within this unit reveals the absence of clear reservoir geobodies, such as sand bars (observed instead within S5) or channels (Figure 5). Although some 
lithological variations can be inferred by observing the change of continuity of facies (highlighted by the chaos attribute), the AAs, the transmission artefacts due to shallower Pleistocene valleys (PVFP), and the iceberg plough marks, dominate the otherwise nearly featureless stratigraphy of the Unit (Figure 5).

Unit 3 was penetrated by wells A15-02, -03, and -04. The main lithology of this unit consists of interbedded light-grey slightly calcareous clay and poorly-to-moderately consolidated very fine to fine-grained sand (Figure 4B). The gamma ray shows for this unit values of 90-120 API indicating an alternation of clay-rich and silty-sand-rich intervals. Unit 3 hosts nearly 50 (49) potential reservoir intervals with thicknesses ranging from 0.3 to $10 \mathrm{~m}$ ( 1 to $32 \mathrm{ft}$ ) and with a net pay of 74 m (240 ft) (32\% of Unit 3). Reservoir intervals within S11 (Core 2 of well A1503; Figure 4B) have a range in permeability of $65-85 \mathrm{mD}$. Tight formations encountered in the same unit are characterised by shale volume fraction $>30 \%$ and by permeability of $0.4-4.69$ $\mathrm{mD}$ (Klinkenberg horizontal permeability; Figure 4B).

\section{Unit 4: Sequences S13-S15}

This is the uppermost package of the Upper North Sea Group, as defined previously, but with the addition of two shallower sequences S14 and S15 to complete the stratigraphy to seabed. S13 is characterised by laterally continuous parallel reflections characterised by moderate amplitudes (Figure 3). S13 shows isopach geometry within the study area and with an approximate thickness of nearly $50 \mathrm{~m}(164 \mathrm{ft})$. Toward the top of S13 the reflectivity is more continuous and the iceberg plough marks are not present (Kuhlmann and Wong, 2008).

The sequence has been drilled by wells A15-02, -03 , and -04 , and is composed of relatively thick sand-rich layers interbedded with clay-rich intervals characterised by similar thickness. S13 hosts 5 potential reservoirs with thickness of 3-10 m (10-32 ft) (Figure 4B). The lack of 
permeability data does not allow us to assess the quality of these reservoir intervals. This sequence is dated as Late Pleistocene in age.

Sequence S14 has a similar seismic facies to Sequence S13 and a gross thickness of nearly $90 \mathrm{~m}$ (295 ft) (Figure 3). This sequence hosts the shallowest AAs documented in this study. The lithology, based on cuttings only (log data in casing only) is consistent with an alternation of sand and clay packages.

Sequence S15 is characterised by nearly parallel geometry and a thickness of $300 \mathrm{~m}(984 \mathrm{ft})$ (Figure 3). The acoustic character of the unit differs from the underlying sequences as it contains a number of fluvial and sub-glacial valleys (PV, Figure 3) which can be recognised on seismic profiles by the strong amplification and because of the concave upward geometry. The presence of highly heterogeneous sub-glacial material deposited in these valleys strongly influences the imaging of the underlying intervals which are affected by transmission artefacts and by velocity effects (pull-ups and push-downs) (Figure 3). The presence of these channels was suggested to be consistent with a fluvial, or paralic, environment (Kuhlmann and Wong, 2008), although similar features have been interpreted in the study area as tunnel valleys, which are of sub-glacial origin (Stuart and Huuse, 2012). This sequence is Late Pleistocene to Holocene in age (top $50 \mathrm{~m}[165 \mathrm{ft}])$.

\section{KEY OBSERVATIONS}

\subsection{General structure of the study area}

The study area is located along the western margin of the Step Graben (Figures 1, 2). Two main fault systems are mapped crossing the study area (Figure 1B). The older system is characterised by normal displacement and strikes nearly N-S. The older system is oriented nearly E-W and is characterised by a normal and dextral strike slip displacement. These fault systems offset the pre-salt and older units, but are detached from the overlying Mesozoic 
intervals by the Zechstein evaporites (Figures 1,2). The Mesozoic sediments are deformed into a series of long wavelength and short wavelength folds with a dominantly N-S axes (e.g. hinge line of Top Chalk syncline, Figure 1) and mimicking the general structure of the underlying Step Graben (Figure 2). Diapirism of the Zechstein evaporites combined with inversion tectonics produced tight anticlines with considerable (>500 $\mathrm{m}[1640 \mathrm{ft}])$ shallowing at the Top Cretaceous (Figure 1, 2).

The structure of the Cenozoic is fairly simple: the anticlines visible at the Late Cretaceous levels persist upward with diminishing structural relief until, near the MMU, they are restricted to weakly deformed domes with a relief of a few tens of metres (Figure 2, 3). There is no evidence of structural reactivation of older trends during the later Cenozoic: rather, the weak doming is interpreted as an expression of differential compaction across the inactive deeper structures (Figure 2). Polygonal faults (Cartwright, 2011) are widely developed in a number of layers (tiers) within the Eocene to Middle Miocene interval, but die out in Sequence 2 (Figure $3,4,5$ ), and do not influence the structure of the AI (Figures 3 and 4). No other faults have been observed penetrating from depth to shallow levels of the Upper North Sea Group. The shallowest level up to which the deep faults propagate is the early Eocene.

\subsection{General description of the stacked AAs}

Four localised zones of stacked AAs are mapped in the study area along with a number of smaller, isolated single layer AAs (Figure 6). These four zones strongly resemble VACs as defined by Foschi et al. (2014), such that they exhibit vertical stacking of individual AAs defining a region of seismic acoustic amplification. The four VACs are restricted to the upper section of the Upper North Sea Group and in particular within the AI previously defined (Figure 6). AAs have not been observed at any deeper levels in the study area. Only VAC 1 is contained entirely within the survey area, and this is described in more detail in the following section, but 
the general characteristics of all four interpreted VACs can be inferred from the available data coverage, and these are summarised below.

\section{Structural context}

The four VACS are all located vertically above pronounced structures (anticlines) at the Late Cretaceous level, but the nature of these deeper structures varies. VAC1 is situated above a pronounced salt cored anticline located to the North and in the centre of the study area (Figure 7). This structural high is characterised by a fold axis which curves and rotates gradually from a SW-NE to E-W direction. The high exhibits an extent of approximately $6 \mathrm{~km}(3.72 \mathrm{mi})$ and a relief of nearly $500 \mathrm{~m}(1640 \mathrm{ft})$ with respect to the surrounding region. VAC 2 is situated above a structural high which is partially imaged by the 3D seismic data. It is an elongated structure oriented approximately N-S and with a relief of $250 \mathrm{~m}(820 \mathrm{ft})$. Also VACs 3 and 4 are situated above structural highs located to the westernmost portion of the study area (Figure 7A). In these cases, the structural highs are less pronounced and shallower than the structural high beneath VAC1. Single AAs highlighted on a minimum-amplitude map calculated along the horizon separating sequences S5 and S6 are also located above structural reliefs (AAs, Figure 7B).

It is also worth noting that there does not appear to be any relationship with the magnitude of the structural relief at Late Cretaceous levels and the position of the VACs. The position of the VACS does not appear to closely conform to structure at the level of any of the hosting horizons (more details later). Structural mapping with tight grids of individual horizons shows indeed that the sequences hosting the AAs within the AI are characterised by a nearly horizontal geometry with a dip of $0.05-0.15$ degrees (Figure 6A-D). This geometry will be discussed more in detail later. 
429 The sets of stacked AAs are composed of 5-7 anomalies characterised by a clear negative 430 polarity (soft acoustic response, indicating a downward reduction in acoustic impedance; 431 Brown, 2004) (Figure 6). The anomalies are visible as a simple amplification of the background 432 reflections and do not produce significant disruption of the reflectivity pattern (Figure 6). They are interpreted on profiles from their very significant increase in amplitude relative to the background values of the correlative reflection (the host reflection). The amplification is not uniform, and ranges from typically 2-8 times the mean background amplitude value (Figure 6E-F). On peak amplitude extractions of the host reflections (Figure 6E-F), the AAs all define regions with a distinct and closed perimeter, separating the region of amplification from the background (Figure 6E-F). The perimeter of each anomaly is interpreted as the so called 'cutoff' position between the background reflection and the amplified reflection. The sharpness of this cut-off varies considerably, from an abrupt shift of 3-4 times the amplitude value in a distance of a few tens of metres (sharp cut-off, Figure 6E-F) to a more gradual tapering cut-off (smooth cut-off, Figure 6E-F) over perhaps hundreds of metres. Regardless of the sharpness of the amplitude cut-off, the margins of the AAs in the basin were based on a threshold set to 3 in acoustic amplitude (Figure 6F).

Interestingly, the amplified portions of individual reflections exhibit a smoother, more continuous response than their correlatives outside the regions of amplification (Figure 6B 447 inset). This effect, previously observed in Figure 5B-C, is here interpreted to be caused by the presence of gas which can produce a shift of the dominant frequencies toward lower values and produce a smoothing of the wave-shape (c.f. Korneev et al., 2004). In association with this effect, the AAs also exhibit an apparent phase rotation, where the wavelet changes from the otherwise zero phase to an approximately $90^{\circ}$ phase (Yilmaz, 1999). This characteristic can be 
checked on relatively isolated anomalies, such as AA1 and 2 of VAC2, where two consecutive trough and peak loops are observed (Figure 6B).

\section{Geometry}

The individual AAs are typically $1-7 \mathrm{~km}(1.60-11.26 \mathrm{mi})$ across their maximum extent and generally subcircular in shape, when observed on map view (Figure 6E). They extend across the AI in all four examples and over a vertical distance of c. $300 \mathrm{~m}$ (c. 984ft) (Figure 6). Individual anomalies are spaced 20-100 m (65-328 ft) from underlying and overlying neighbours, and are demonstrably stacked vertically, in that there is a high degree of spatial overlap from one anomaly to the next in the vertical succession (Figure 6).

The AAs within each VAC are consistently distributed in a way that the amplified regions crudely resemble a pile of dishes. The ratios of vertical to maximum horizontal extent of the VACs range from 0.04 to 0.14 (true-scale insets, Figure 6A-D). VACs may show also a certain degree of symmetry when observed on arbitrary vertical cross section (e.g. VAC 2, Figure 6B). Importantly, the larger AAs are located toward the base of the VACs (Figure 6A-D).

\subsection{Detailed description of VAC1}

VAC1 is described in detail in this section because it is the only one of the four VACs in the study area to be completely imaged by the 3D seismic data and, most importantly, it is calibrated by the exploration wells with the most extensive core, petrophysical and geochemical analyses of fluid samples. The continuity of the internal structure of VAC1 is disrupted by overburden artefacts associated with a shallower tunnel valley or channel features (Figure 2, 3). These artefacts have been noted and described from the same stratigraphic interval by Stuart and Huuse (2012), and include velocity push down, scattering and attenuation, and migration artefacts due to the perturbed velocity field. 
The acoustic character of AAs is a first diagnostic stage of the interpretation to assess the nature of the amplification (Sheriff, 1975). VAC1 consists of a series of seven major verticallystacked AAs (AA1-7; Figures 8). On seismic profile the anomalies are simple amplification of the background reflectivity and are generally composed of two consecutive amplified loops of opposite polarity (Figure 8A, inset). Because the seismic data was finalised in processing at zero phase, the observed double-loop of the AAs, typical of $90^{\circ}$ phase seismic data, is interpreted to be related to a tuning effect (Sheriff, 1975) generated by the metres-thick ( 0.3 to $10 \mathrm{~m}$ [1 to $32 \mathrm{ft}]$ ) reservoir-seal intervals hosted within the host sequences (see Figure 4 for more details).

The AAs are characterised by a closed perimeter when observed on map view (Figure 8C-

D). The closed perimeter of the AAs does not resemble typical reservoir geobodies, such as lobes, fans or channels (see also later). The amplification of the AAs, 4-to-8 times the background value (Figure 6F), is sufficiently high to produce an apparent enhanced continuity of the hosting horizons. This effect is best observed on the chaos attribute map which shows an apparent reduction of chaotic facies within the amplified region (Figure 5B-C).

The amplification of the AAs is characterised by patches of medium to high amplitude response which does not show any similarity in pattern to the acoustic response of the hosting unit. This can be observed in Figure 8C-D where the acoustic character of the AAs is not geometrically related to the acoustic variation of the hosting horizons (acoustic change, Figure 8C-D). The amplification cut-off is reached within 500-750m (1640-2460 ft), as previously observed in Figure 6F (VAC1), and is generally smooth if compared with AAs of other VACs (e.g. Figure 6F, VAC2). 

velocity push-down effect (Sheriff, 1975) associated with amplitude attenuation (Att. \& PD, Figure 8A-B). Part of this effect is related, as described before, to the shallower Pleistocene valleys (PV). However, as observed in Figure8 C-D a nearly closed region of attenuation can be observed. In this case the attenuation is related to shallower anomalies of VAC1 (e.g. AA2 and AA3). conform to structure (England et al., 1987). In order to do so, the time-structure maps of the horizons within the anomaly intervals were converted to depth using a $1 \mathrm{D}$ velocity function based on the compressional velocity, Vp, obtained from the wireline logs of wells A15-2, 3 and 4. The margins of the AAs were then superimposed on the depth structural map of their relative hosting horizons.

This analysis reveals that the margins of the AAs do not conform to structure. If the AAs did conform to structure, their margins would follow at least one of the depth contours of the host unit. Here, however, the margins clearly exhibit divergent patterns with respect to the host structure, as illustrated for two AAs in Figure 9A-B. This can be observed on the northern margin of AA7 (red arrows; Figure 9A) and at the western margin of AA5 (red arrows; Figure 9B). The depth contours also cut across the AA margins in places, as at the centre of AA5 where the -540 m (1770 ft) contour cuts across the body of the anomaly (red circle; Figure 9AB). This interpretation may be subject to small errors due to the lack of a 3D velocity model for time-to-depth conversion. However, the hosting sequences exhibit a nearly horizontal geometry so that variation in velocity should produce only a static shift in the depth of the surfaces. 
Excluding those regions where transmission artefacts are dominant, such as those related to pull-ups caused by the Pleistocene valleys, our interpretation suggests that if the AAs are related to an invading non-wetting fluid (e.g., gas), then it has been unable to fill the available structure (e.g. Hermanrud et al., 2014). This interpretation is discussed later.

$3 D$ geometry and geostatistical analysis of VAC1

Vertical stacking of AAs was previously interpreted by Foschi et al (2014) to be evidence

of vertical migration across layered sequences. Here, VAC1 shows vertical stacking for all the constituent AAs. With the exception of AA1, the AAs also exhibit a systematic increase in size with depth, with apparent areas ranging from $1.25 \mathrm{~km}^{2}\left(0.77 \mathrm{mi}^{2}\right)$ (AA2) to $32 \mathrm{~km}^{2}\left(19 \mathrm{mi}^{2}\right)$ (AA7) (Figure 10C). Because AA2, AA3 and AA4 are composed of two subanomalies each, the geometry of VAC1 can be synthesised as a double-cone-shaped structure with vertices oriented upward (Figure 10).

To investigate the stacking pattern of VAC1 in more detail, the centroid of each AA was calculated from the shape of its margins (see methods). The centroid is a convenient metric because it synthesises to one single point ( $\mathrm{x}, \mathrm{y}$ coordinates) the complex geometry of the observed AAs. For AAs made of up two subcircular sub-anomalies within the same interval (e.g. AA2), a centroid was calculated for each sub-anomaly. Centroids were also calculated for minor AAs (black crosses, Figure 10A-D-E); these are not included in the following description.

The centroids of the main AAs (red and blue crosses, Figure 10D) are distributed along an elongated, $2.5 \mathrm{~km}(1.55 \mathrm{mi})$ corridor. The corridor is oriented NE-SW and located approximately in the central region of VAC1 (Figure 10D).

Given that (1) the location of the centroid is based on the present-day AA geometry and that 
551 AA5, AA6 and AA7 (blue crosses, Figure 10E) as the product of the coalescence of two initially separated AAs. This interpretation is supported by the geometry of AA1 and AA5, where the two lobes of the anomalies are interpreted as a result of the coalescence of two initially separated anomalies (AA5; Figure 10A). This interpretation supports the case that the centroids of VAC1 are most likely to be distributed within two regions, namely CG1 and CG2 (Figure 10D).

\section{Calibration of VAC1}

VAC1 was intersected by the exploration boreholes A15-02 and A15-03 (inter-well distance

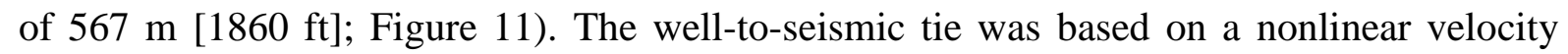
function, unlike in previous works (e.g. Kuhlmann and Wong, 2008 applied a constant velocity of $2 \mathrm{~km} / \mathrm{s}[6560 \mathrm{ft} / \mathrm{s}])$, and provided a correlation value for the interval of interest of approximately 0.8 (Figure 11B-C).

The well intersected five of the seven AAs composing VAC1 (Figure 11A). All of the drilled AAs (AA1, 4, 5,6 and 7) are located at depth intervals where the circulation mud exhibits the presence of gas (Figure 11D). This "gas-show" confirms that the intersected AAs are related to gas. Gas analysis performed by the operators at AA7 (678 m MD [2224 ft]) indicates a composition dominated by $\mathrm{C} 1$ ( $>99 \%$ by volume), but also trace amounts of $\mathrm{C} 3, \mathrm{iC} 4$ and $\mathrm{nC} 4$ (Figure 4, inset). Isotopic analysis was not performed on-site, but dry gas (C1 > 99\%) depleted in ${ }^{13} \mathrm{C} / \mathrm{C} 1$ has been documented in this region (Ten Veen et al., 2014).

The relation of the AAs with hydrocarbons was successfully confirmed by the gas-show and by the seismic data. The limited vertical resolution of these two exploration methods (e.g., $7 \mathrm{~m}$ [22 ft] for seismic data in the interval of interest) may not allow the identification of thin gasfilled intervals. For this reason, the scaled neutron porosity and density logs were combined to estimate the presence of gas with a higher resolution (Figure 11D; see methods). The results of 
this operation, based on the identification of crossovers between neutron porosity and density logs (Figure 11D), confirm that gas-bearing layers are present the same depth intervals where the gas-shows were recorded. Importantly, these results also reveal the presence of many other potential gas-charged layers distributed within VAC1; for example, the interval AA1-AA4 exhibits about 13 gas-crossovers (Figure 11D).

\section{Reservoir properties from core data (VAC1)}

To define the characteristics of the reservoirs layers in more detail, the gas-shows were then calibrated with the previously defined reservoir and seal intervals (Figure 4B) and compared with the sedimentary structure derived from the core data. The results indicate that the gasrelated AAs of VAC1 are hosted by both single and multiple reservoirs. AA2 and AA4 are hosted by a single reservoir each, whereas AA5-6-7 are hosted by thinner multi-reservoir intervals. This can be observed comparing the reservoirs associated with AA1 and AA4, characterised by thicknesses of 3.4-1.8 m (11-6 ft), with the multiple and thinner reservoirs of AA6 and AA7, characterised by thicknesses of 1-0.5 m (3.2-1.5 ft). Also, the internal average porosities of the reservoir intervals associated with gas-shows decrease with depth. This can be observed by averaging the porosity measured by the neutron porosity log (Figure 11E).

Within the gas-show intervals, only cores 2 and 4 recovered information about the stratigraphic structure of the reservoir intervals, and hydraulic analyses were only performed on core 2 (Figure 4B and 11F). Two of the three reservoir intervals can be described within core 2 (AA5). These reservoirs, as observed directly on core images, are consistent with siltstone and argillitic siltstone characterised by ripple sedimentary structures (Figure 11F). These reservoir layers are embedded within parallel laminated argillitic siltstones and claystones characterised by moderate-to-intense borrowings. The core data highlight also the modest thickness of the beds which ranges from 5 to $40 \mathrm{~cm}$ ( 2 to 15 in; Figure 11F). The results 
of the calibration of VAC1 support the case that the gas related to the encountered AAs is

602

603

604

605

606

607

608

609

610

611

612

613

614

615

616

617

618

619

620

621

622

623

624

625

hosted by low-quality reservoirs.

\section{DISCUSSION}

The preceding sections highlight the main structural and stratigraphic features of the study area and provide a description of the observed VACs and their distribution in the study area. Two main points are discussed in the following section, namely: (1) the mechanisms contributing to the formation of the VACs and (2) the significance of the VACs in the wider context of vertical hydrocarbon migration across layered sequences. We discuss the formation of VACs starting from the geometry of the AAs and extending the use of the centroid from single to multiple AAs. These arguments will be fundamental for the formation of VACs.

\subsection{Significance of the shape of AAs}

The AAs of the VACs exhibit characteristic closed shapes with geometries that are either one subcircle or a combination of two subcircles (Figures 5, 8, 9, and 10). The closed perimeter for hydrocarbon-related AAs is typically observed in 4-way-dip closure structures, such as a folded anticline with a flat hydrocarbon-water contact (e.g., England et al., 1987). The flat hydrocarbon-water contact develops in settings where the layer dip is sufficient for buoyancy to overcome capillary forces (Tsimpanogiannis and Yortos, 2004) and allow for the lateral migration of hydrocarbons and their subsequent accumulation in structural traps (Schowalter, 1979).

The AAs of VAC1 are located near to the top of structural highs, as shown in Figure 9, but the related gas-water contacts do not conform to structure. This observation was previously highlighted by cross-cutting and divergent patterns between the margins of the AAs and depth contour lines of the host units (Figure 9). The lack of a gas-water contact conforming to 
structure may reflect the poor quality of the reservoir intervals, as shown previously (Figure $11 \mathrm{~F})$, or, more importantly, their limited dip ( 0.1 degree, Figure 9A-B). AAs (e.g. AA7 $>30 \mathrm{~km}^{2}$ ) in poor-quality reservoir intervals where the gas is not able to completely fill the observed trap structures. In order to explain this, the typical buoyancy pressure within each AA was compared to the typical capillary pressure. The buoyancypressure field was calculated in the standard way as $P=\Delta \rho g h$ (e.g., Bear, 1972), where $\Delta \rho$ is the difference in density between the water and the gas, $g$ is the standard acceleration due to gravity, and $h$ is the vertical height of the AA. The density difference $\Delta \rho$ is estimated using empirical relations for pure methane and brine water densities (Mavko et al., 2009) based on in-situ condition at the centre of VAC1. The height $h$ is estimated as the difference in elevation across the length of the AA, as calculated from the lengths of the minor and major axes of the AA and the dip angle of its reservoir interval. The gas can flow only when its buoyancy pressure is large enough to overcome the capillary entry pressure of its reservoir interval, so we also estimate the capillary entry pressure of a representative reservoir; for this purpose, we use the reservoir hosting AA5 (core c2, Figure 11F). The capillary entry pressure was calculated as $P c=2 \gamma / r$ (e.g., Berg, 1975), where $\gamma$ is the interfacial tension, the pore-throat radii $r$ were derived empirically from the grain-size distribution (e.g., Nelson 2009) since pore-throat radii themselves were not directly available.

The obtained crossplot is used as follow: (1) any point in the plot represents a buoyancy pressure generated by a given gas column, but where the column is expressed as function of length (or lengths in case of 2D geometry) of the gas accumulation and slope (or angle) of the hosting reservoir; (2) the definition of a capillary entry pressure (Pce) define whether a given gas accumulation is geometrically capable (buoyant), or not (trapped), of generating buoyancy 
of VAC1 shows that, except for AA7, all of the AAs are likely to be laterally trapped by

652

653

654

655

656

657

658

659

660

661

662

663

664

665

666

667

668

669

670

671

672

673

674

675

capillary forces because the reservoir dip is too shallow to generate sufficient buoyancy (ie, the typically capillary entry pressure exceeds the typical buoyancy pressure; Figure 12A). This may be a reservoir-scale manifestation of capillary pinning, which, as has been documented in laboratory experiments (Zhao et al., 2014), is able to stop the lateral advance of buoyant nonwetting fluids at a finite distance. These results imply that lateral migration, within the AI, is possible only for large and connected gas accumulations. The observed AAs cannot form by lateral migration of buoyant free phase gas.

An alternative explanation for the presence of gas in the VACs is related to the generation of biogenic gas at the depth range of the AI. However, the base of the AI is too shallow for biogenic gas generation according to the model of ten Veen et al (2014), which would place the top of the generation window for biogenic gas at $840 \mathrm{~m}(2755 \mathrm{ft})$. This upper limit is nearly $200 \mathrm{~m}$ (656 ft) below the base of the deepest AAs of the VACs encountered in the study area (AA5 of VAC3; Figure 6). Even if the top of the biogenic generation window were located at a shallower depth (e.g. within the AI), because the gas is not able to migrate laterally (Figure 12A), it is hard to argue that the biogenic gas is produced just at the places where the VACs are observed (Figure 7).

\subsection{Analysis of the centroids and vertical conduits}

Given the arguments above, we conclude that the gas hosted in the reservoir layers is neither (1) generated at the AI, nor (2) able to migrate laterally. We therefore propose that the observed AAs are most likely to be the result of an injection of gas into the reservoir layers from below. Motivated by this, we seek the most likely injection point.

Laboratory experiments show that gas injection into a vertically confined, nearly horizontal, and hydraulically isotropic medium produces a gas region that is roughly radially symmetric 
676 (e.g., Zhao et al., 2016; Figure 12B). In these experiments, the centroids of the gas regions 677 (calculated with the same method applied to the AAs of the VACs) coincide with the injection points, as shows in Figure 12B (red crosses). A similar geometry can be also observed in isolated AAs of VACs. AA3 and AA4 of VAC1 (Figure 10A) exhibit perimeters of approximately circular shape and, importantly, their centroids are nearly at the centre of the AAs. Based on this, and considering the nearly horizontal geometry of the reservoir intervals, we suggest that the most obvious place to locate the injection points to form the observed AAs is at their centroids.

The distribution of the centroids of VAC1 was previously interpreted and described to be focussed into two main regions (Figure 10D). Because the centroids (1) represent, as discussed, the locations where the injection of the gas takes place, and (2) occur at different depths, they indicate the presence of preferential vertical conduits, or pathways where the migration of gas across (discussed later) and into (injection) the reservoir layers take place (Figure 12C).

Vertical conduits

The vertical conduits represent the place at different depth intervals where the gas is injected 692 into the reservoirs, but importantly where the gas is able to migrate across the sealing layers documented through the analysis of well data (Figure 4B, 11E). The vertical conduits may represent a seal bypass system (SBS), defined by Cartwright et al. (2007) as the place where cross-stratal migration is most likely to occur.

The conduits, because of their vertical component, may consist of pipe-like structures such as those described by Moss and Cartwright (2010) from offshore Namibia. Pipes act as conduits and are associated with a vertical propagation of hydraulic fractures produced by the migrating 
typically appear on seismic cross-section as vertical regions of signal disturbance (Løseth et al., 2009).

Pipes have not been documented within the present study area (Figures 3, 5). This suggests that if any vertical conduits are present, they may be invisible at the scale of the survey (e.g. they may be sub-resolution features, $<8-10 \mathrm{~m}[26-32 \mathrm{ft}]$ in diameter). Another possibility is that the vertical conduits consist of regions where focussed vertical gas migration occurred without perturbing the initial permeability structure. In this case, cross-stratal migration may be dominated by vertical capillary invasion (e.g. Berg, 1975; Jain and Juanes, 2011).

Although neither of these two contrasting migration styles - hydraulic fracturing and capillary invasion - can be excluded because of the presence of potential sub-resolution features, both mechanisms would need to provide a vertical migration route in order to satisfy the consistent observations of a vertically stacked centroid geometry observed for VAC1 (Figure 10D). This suggests that the cross-stratal migration process is insensitive to the variable hydraulic property of the sealing units, including both core-scale heterogeneities (Figure 11F) and layer scale heterogeneities ( $\mathrm{m}$ to $\mathrm{km}$ ), such as the well-developed iceberg plough marks (Haavik and Landrø, 2014; Figure 5, 8).

\subsection{Sequential vertical gas charge into the AI}

One of the most important observations of the VACs in the study area is that they all exhibit an upward-tapering geometry (Figure 6), where the area of each successive AA decreases upward (Figure 10). The geometry of the VACs may reflect the properties of each individual reservoir interval, such as permeability or thickness. Because flow rate is directly proportional to permeability (Darcy, 1856), reservoirs characterised by high permeability are more likely to host larger gas accumulations. The upward-tapering geometry of the VACS would therefore imply an upward-decreasing trend in the quality of the reservoir intervals. 

$6 \mathrm{ft})$ for AA1 and AA4 to $1-0.5 \mathrm{~m}(3.2-1.5 \mathrm{ft})$ for AA6 and AA7. This reduction in reservoir thickness with depth is also associated with a decrease in reservoir porosity in the same direction. This was observed by extracting the average porosity from the calibrated neutron porosity log within the reservoir intervals (Figure 11E). Permeability data was not measured for all the encountered reservoir intervals, so we cannot establish here whether the permeability of the reservoirs follows a constant or a variable behaviour with depth. However, the typical linear relations between permeability and porosity for siliciclastic facies (e.g. Nelson, 1994) suggest that the permeability also decreases with depth and, ultimately, that the quality of the reservoir intervals is most likely to be lower in the deeper reservoirs. This is in contrast to the upward tapering geometry of the VACs (Figure 6).

Another factor that may affect the geometry of the VACs is a combination of (1) the upward direction of the migration of the hydrocarbons, and (2) the layered structure of the AI. The AAs of the VACs are most likely formed by vertical migration of gas into the AI, as discussed above (Figure 12C). Because the migration is oriented upwards, the gas will invade the first available reservoir interval, which will be near the base of the sequence package where the reservoir layers are embedded (AI). The formation of the lower gas-related AAs will therefore precede the shallower ones. This means that the lower gas-related AAs have more time to accumulate hydrocarbons and more time to grow in size with respect to the shallower ones. In doing so, explain why, in most of the documented VACs in this study, the deeper AAs are characterised by the largest lateral extent (Figure 6). We envisage that large variations in reservoir quality, or the presence of structural elements such as faults, may ultimately control the final geometry 
of the VACs. This was suggested by Foschi et al (2014), where a well-developed network of polygonal faults was proposed to be a major control on both the cross-stratal (SBS) and lateral migration (seal). We therefore propose that the sequential vertical gas charge controlled by vertical conduits is most likely to dominate the geometry of the VACs in settings such as the AI, which are characterised by horizontal layering, lack of strong lateral heterogeneities, and absence of structural elements (Figure 3, 4, 5).

\subsection{Source of gas and timing}

We discuss now the potential source of the gas in place in the observed VACs and more generally in the study area. Because the gas is not originated within the AI an alternative source has to be present beneath the VACs. Importantly, whatever is the nature of the source, the produced gas must also be focussed where the documented VACs are observed (Figure 7).

\section{Source of gas}

The migration process forming the documented VACs can be associated with (1) biogenic microbial activity present in the region immediately below the AI, or (2) thermogenic cracking of source rock present in the deeper section of the basin (Gerling et al., 1999).

Isotopic analyses conducted in the region (Verweij et al., 2013) pointed to a dry gas (methane 99\%) depleted in ${ }^{13} \mathrm{C} / \mathrm{C}$. This suggests that the gas is derived from biogenic sources. Biogenic sources have been documented to be present in the study area and active nowadays at a ceiling depth of $840 \mathrm{~m}(2755 \mathrm{ft})$ (ten Veen et al., 2014). However, lateral migration was previously considered not to be favoured in the AI because of the low angle of the nearly horizontal reservoir layers (Figure 12A). This is even more pronounced below the AI where a limited number of reservoir intervals (Figure 4B) and pore-throat radii about $0.1 \mu \mathrm{m}$ were documented (e.g. sequence S6 at depths of 871.5-912.7 m [2857-2992 ft]; Figure 12A). These 
features makes complicate to argue that lateral migration can deliver gas to those places where the VACs are observed. We therefore suggests that vertical migration is more likely to occur (Illing, 1939).

Based on this argument one approach to identify the potential source of the gas is to look at the main structural elements within the basin and correlate these with the distribution of the VACs and the AAs. As observed before (Figure 7), the VACs and the AAs exhibit a close match with the location of the salt structures at the Base Chalk (Figure 2, 7A-C-D). Because we expect primarily vertical migration (see previous argument), it is likely that the origin of the gas is located below the base of the Chalk Group. We propose therefore that the focussing of the gas occurs at this deeper level, where prominent structures can drive and focus fluids to structural highs (England et al., 1987; Hovland and Judd, 1988; Løseth et al., 2009).

Given the arguments above, it is likely that the gas that forms the shallower VACs and AAs is related to a deep source. Other authors working in this region (e.g. Schroot \& Schüttenhelm, 2003; Verweij et al., 2012) never excluded the presence of thermogenic gas forming the documented VACs, however, because of the biogenic component of the gas in place, we cannot demonstrate with the available data that the gas is thermogenic.

\section{Timing}

It is challenging to define the timing of the migration of gas into the upper section of the Upper North Sea Group and the formation of the VACs in the study area, primarily because of the lack of extensive information on gas composition (e.g. Barry et al., 2016). Also, the VACs and AAs do not produce substantial structural deformation that could be used to define a precise period in time for the start of the migration process.

The age of the reservoir interval is dated as Gelasian to early Calabrian (Figure 4). This implies that the onset of the migration and the emplacement of the VACs occurred after this 
800

801

802

803

804

805

806

807

808

809

810

811

812

813

814

815

816

period. The entrapment of gas in sediments is often controlled by the activity of the basin (Andresen et al., 2012). Based on the age of the reservoir intervals ( 2.1Ma), a triggering mechanism for the migration of gas had to take place in the last $2 \mathrm{Ma}$. Because of the negligible tectonic activity of the basin in the last 2Ma (e.g. Stuart and Huuse, 2012), an external event had to take place.

In the last 1.1Ma, the basin underwent multiple cycles of advance and retreat of regional ice sheets during the Elsterian, Saalian and Weichselian glaciations. These ice sheets have been documented to be generally $>500 \mathrm{~m}$ thick and able to produce deep valleys during their movement (Graham et al., 2010). Evidence of ice-sheet movement in the basin has been proven because of the presence of near-surface V-shaped valleys (Figure 2, 3). The unloading produced by the removal of the ice sheet could have decreased the confining pressure on gasbearing sediments (Ostanin et al., 2013; Portnov et al., 2016), allowing the gas to expand and migrate upward to form the observed VACs. This represents the only proposed hypothesis to constrain the timing and the emplacement of the VACs.

\section{CONCLUSIONS}

The following conclusions are proposed:

(1) The stacked AAs in the study area are classified as vertical anomaly clusters following the definition of Foschi et al (2014).

(2) The VACs are related to the presence of methane (>99\%) hosted in low-quality siltrich reservoir intervals. The reservoir intervals are embedded into argillitic siltstone and claystone layers.

(3) The geometry of the VACs tapers upwards, with the size of the AAs increasing with depth. The geometry of the VACs is consistent with a sequential vertical gas charge controlled by central conduits. 
(4) The source of the gas is most likely to be located below the Base Chalk, but extensive gas analyses are required to provide further evidence for or against this argument. The formation of the VACs may be consistent with the activity of ice-sheets during the Elsterian, Saalian, and Weichselian glaciations.

829 


\section{References}

Andresen, K. J., 2012, Fluid flow features in hydrocarbon plumbing systems: What do they tell us about the basin evolution?: Marine Geology, v. 332-334, p. 89-108.

Andresen, K. J., and M. Huuse, 2011, 'Bulls-eye' pockmarks and polygonal faulting in the Lower Congo Basin: Relative timing and implications for fluid expulsion during shallow burial: Marine Geology, v. 279, p. 111-127.

Backus, G. E., 1962, Long-wave elastic anisotropy produced by horizontal layering: Journal of Geophysical Research, v. 67, p. 4427-4440.

Barry, P. H., M. Lawson, W. P. Meurer, O. Warr, J. C. Mabry, D. J. Byrne, and C. J. Ballentine, 2016, Noble gases solubility models of hydrocarbon charge mechanism in the Sleipner Vest gas field: Geochimica et Cosmochimica Acta, v. 194, p. 291-309.

Bear, J., and C. Braester, 1972, On the Flow of Two Immscible Fluids in Fractured Porous Media: Developments in Soil Science, v. 2, p. 177-202.

Berg, R. R., 1975, Capillary pressures in stratigraphyc traps: AAPG Bulletin (American Association of Petroleum Geologists), v. 59, p. 939-956.

Bonham, L., 1980, Migration of hydrocarbons in compacting basins: AAPG Bulletin, v. 64, p. 549-567.

Brown, A. R., 2004, Interpretation of three-dimensional seismic data: AAPG Memoir/SEG Investigations in Geophysics No. 9, AAPG, 560 p.

Cartwright, J., 2011, Diagenetically induced shear failure of fine-grained sediments and the development of polygonal fault systems: Marine and Petroleum Geology, v. 28, p. 1593-1610.

Cartwright, J., M. Huuse, and A. Aplin, 2007, Seal bypass systems: AAPG Bulletin, v. 91, p. 11411166.

Cartwright, J., and C. Santamarina, 2015, Seismic characteristics of fluid escape pipes in sedimentary basins: implications for pipe genesis: Marine and Petroleum Geology, v. 65, p. 126-140.

Cramer, B., S. Schlömer, and H. S. Poelchau, 2002, Uplift-related hydrocarbon accumulations: The release of natural gas from groundwater, Geological Society Special Publication, p. 447-455.

Darcy, H., 1856, Les fontaines publiques de la ville de Dijon: exposition et application: Victor Dalmont. $647 \mathrm{p}$.

Demaison, G., and B. J. Huizinga, 1991, Genetic classification of petroleum systems (1): AAPG bulletin, v. 75, p. 1626-1643.

Doornenbal, J., O. Abbink, H. Pagnier, and J. van Wees, 2009, Petroleum Geological Atlas of the Southern Permian Basin Area-overview SPB-Atlas Project-Organisation and Results: 4th EAGE North African/Mediterranean Petroleum and Geosciences Conference and Exhibition Tunis 2009.

Edmundson, H. t., and L. Raymer, 1979, Radioactive logging parameters for common minerals: The Log Analyst, v. 20, p. 38-47.

England, W. A., A. S. Mackenzie, D. M. Mann, and T. M. Quigley, 1987, The movement and entrapment of petroleum fluids in the subsurface: Journal of the Geological Society, v. 144, p. 327347.

Etiope, G., and G. Martinelli, 2002, Migration of carrier and trace gases in the geosphere: An overview: Physics of the Earth and Planetary Interiors, v. 129, p. 185-204. 
Evans, D., P. Hopson, G. Kirby, and C. Bristow, 2003, The development and seismic expression of synsedimentary features within the Chalk of southern England: Journal of the Geological Society, v. 160, p. $797-813$.

Foschi, M., and J. A. Cartwright, 2016, South Malvinas/Falkland Basin: Hydrocarbon migration and petroleum system: Marine and Petroleum Geology, v. 77, p. 124-140.

Foschi, M., J. A. Cartwright, and F. J. Peel, 2014, Vertical anomaly clusters: Evidence for vertical gas migration across multilayered sealing sequences: AAPG Bulletin, v. 98, p. 1859-1884.

Gerling, P., M. Geluk, F. Kockel, A. Lokhorst, G. Lott, and R. Nicholson, 1999, 'NW European Gas Atlas'-new implications for the Carboniferous gas plays in the western part of the Southern Permian Basin: Geological Society, London, Petroleum Geology Conference series, p. 799-808.

Goodway, B., T. Chen, and J. Downton, 1997, Improved AVO fluid detection and lithology discrimination using Lamé petrophysical parameters;" $\lambda \rho ", " \mu \rho ", \&$ " $\lambda / \mu$ fluid stack", from $P$ and $S$ inversions, SEG Technical Program Expanded Abstracts 1997, Society of Exploration Geophysicists, p. 183-186.

Graham, A. G., L. Lonergan, and M. S. Stoker, 2010, Depositional environments and chronology of Late Weichselian glaciation and deglaciation in the central North Sea: Boreas, v. 39, p. 471-491.

Haavik, K. E., and M. Landrø, 2014, Iceberg ploughmarks illuminated by shallow gas in the central North Sea: Quaternary Science Reviews, v. 103, p. 34-50.

Helander, D.P., 1983. Fundamentals of formation evaluation: Tulsa, Oil \& Gas Consultants Intl, 332 p.

Hermanrud, C., M. E. Halkjelsvik, K. Kristiansen, A. Bernal, and A. C. Strömbäck, 2014, Petroleum column-height controls in the western Hammerfest Basin, Barents Sea: Petroleum Geoscience, v. 20, p. 227-240.

Hovland, M., and A. G. Judd, 1988, Seabed pockmarks and seepages: impact on geology, biology and the marine environment: Seabed pockmarks and seepages: impact on geology, biology and the marine environment: London, Dordrecht, Boston: Graham \& Trotman (Kluwer), 336 p.

Illing, V. C., 1939, Some factors in oil accumulation: Journal of the Institute of Petroleum, v. 25 , no. 186, p. 201-255. Reprinted in E. A. Beaumont and N. H. Foster, eds., Geochemistry: AAPG Treatise of Geology Reprint Series 8, p. 503-527

Isaksen, G., R. Patience, G. Van Graas, and A. Jenssen, 2002, Hydrocarbon system analysis in a rift basin with mixed marine and nonmarine source rocks: The South Viking Graben, North Sea: AAPG bulletin, v. 86, p. 557-592.

Jahn, F., M. Cook, and M. Graham, 2008, Hydrocarbon exploration and production, v. 55, Elsevier, 456 p.

Jain, A. K., and R. Juanes, 2009, Preferential mode of gas invasion in sediments: Grain-scale mechanistic model of coupled multiphase fluid flow and sediment mechanics: Journal of Geophysical Research B: Solid Earth, v. 114.

Korneev, V. A., G. M. Goloshubin, T. M. Daley, and D. B. Silin, 2004, Seismic low-frequency effects in monitoring fluid-saturated reservoirs: Geophysics, v. 69, p. 522-532.

Kuhlmann, G., P. L. de Boer, R. B. Pedersen, and T. E. Wong, 2004, Provenance of Pliocene sediments and paleoenvironmental changes in the southern North Sea region using Samarium-Neodymium $(\mathrm{Sm} / \mathrm{Nd})$ provenance ages and clay mineralogy: Sedimentary Geology, v. 171, p. 205-226. 
Kuhlmann, G., C. Langereis, D. Munsterman, R. J. van Leeuwen, R. Verreussel, J. Meulenkamp, and T. Wong, 2006, Chronostratigraphy of Late Neogene sediments in the southern North Sea Basin and paleoenvironmental interpretations: Palaeogeography, Palaeoclimatology, Palaeoecology, v. 239 , p. $426-455$.

Kuhlmann, G., and T. E. Wong, 2008, Pliocene paleoenvironment evolution as interpreted from 3Dseismic data in the southern North Sea, Dutch offshore sector: Marine and Petroleum Geology, v. 25 , p. 173-189.

Larionov, V. V. 1969. Radiometry of boreholes (in Russian): Moscow, NEDRA 238 p.

Liu, X., and P. B. Flemings, 2007, Dynamic multiphase flow model of hydrate formation in marine sediments: Journal of Geophysical Research B: Solid Earth, v. 112, p. 1-23

Løseth, H., M. Gading, and L. Wensaas, 2009, Hydrocarbon leakage interpreted on seismic data: Marine and Petroleum Geology, v. 26, p. 1304-1319.

Macelloni, L., A. Simonetti, J. H. Knapp, C. C. Knapp, C. B. Lutken, and L. L. Lapham, 2012, Multiple resolution seismic imaging of a shallow hydrocarbon plumbing system, Woolsey Mound, Northern Gulf of Mexico: Marine and Petroleum Geology, v. 38, p. 128-142.

Mavko, G., T. Mukerji, and J. Dvorkin, 2003, The Rock Physics Handbook: Tools for Seismic Analysis in Porous Media: Cambridge, Cambridge University Press, 524 p.

McAuliffe, C. D., 1979, Oil and gas migration--chemical and physical constraints: AAPG Bulletin, v. 63, p. 761-781.

Miller, S. L., and R. R. Stewart, 1990, Effects of lithology, porosity and shaliness on P-and S-wave velocities from sonic logs: Canadian Journal of Exploration Geophysics, v. 26, p. 94-103.

Mitchum Jr, R., 1977, Seismic stratigraphy and global changes of sea level, Part 2: The depositional sequence as a basic unit for stratigraphic analysis, Seismic stratigraphy-applications to hydrocarbon exploration: Mem. Amer. Assoc. Petrol. Geol., p. 53-62.

Moss, J. L., and J. Cartwright, 2010, 3D seismic expression of km-scale fluid escape pipes from offshore Namibia: Basin Research, v. 22, p. 481-501.

Nelson, P. H., 2009, Pore-throat sizes in sandstones, tight sandstones, and shales: AAPG bulletin, v. 93, p. 329-340.

Ostanin, I., Z. Anka, R. di Primio, and A. Bernal, 2013, Hydrocarbon plumbing systems above the Snøhvit gas field: Structural control and implications for thermogenic methane leakage in the Hammerfest Basin, SW Barents Sea: Marine and Petroleum Geology, v. 43, p. 127-146.

Overeem, I., G. J. Weltje, C. Bishop-Kay, and S. Kroonenberg, 2001, The Late Cenozoic Eridanos delta system in the Southern North Sea Basin: a climate signal in sediment supply?: Basin Research, v. 13, p. 293-312.

Parnell, J., 2002, Fluid seeps at continental margins: towards an integrated plumbing system: Geofluids, v. 2 , p. $57-61$.

Portnov, A., S. Vadakkepuliyambatta, J. Mienert, and A. Hubbard, 2016, Ice-sheet-driven methane storage and release in the Arctic: Nature Communications, v. 7, p. 10314

Posamentier, H. W., and G. P. Allen, 1999, Siliciclastic sequence stratigraphy: concepts and applications, v. 7: Tulsa, SEPM (Society for Sedimentary Geology), 212 p. 
Roberts, W., and R. Cordell, 1980, Problems of petroleum migration: introduction: AAPG Series in Geology, v. 10, p. 6-8.

Schowalter, T. T., 1979, Mechanics of secondary hydrocarbon migration and entrapment: AAPG Bulletin, v. 63, p. 723-760.

Schroot, B., and R. Schüttenhelm, 2003, Expressions of shallow gas in the Netherlands North Sea: Netherlands Journal of Geosciences, v. 82, p. 91-105.

Sheriff, R. E., 1975, Factors affecting seismic amplitudes: Geophysical Prospecting, v. 23, p. 125-138.

Sørensen, J. C., U. Gregersen, M. Breiner, and O. Michelsen, 1997, High-frequency sequence stratigraphy of Upper Cenozoic deposits in the central and southeastern North Sea areas: Marine and Petroleum Geology, v. 14, p. 99-123.

Stemmerik, L., J. Ineson, and J. Mitchell, 2000, Stratigraphy of the Rotliegend Group in the Danish part of the northern Permian Basin, North Sea: Journal of the Geological Society, v. 157, p. 1127-1136.

Stuart, J. Y., and M. Huuse, 2012, 3D seismic geomorphology of a large Plio-Pleistocene delta-'Bright spots' and contourites in the Southern North Sea: Marine and Petroleum Geology, v. 38, p. 143 157.

ten Veen, J., G. de Bruin, J. Verweij, and T. Donders, 2014, Towards a better understanding of shallow seismic anomalies in the dutch offshore: EAGE Shallow Anomalies Workshop.

Triplehorn, D., 1965, Origin and Significance of Glauconite in the Geologic Sequence. Tulsa Geological Society Digest, v. 33, p. 282-283.

Tsimpanogiannis, I. N., and Y. C. Yortsos, 2004, The critical gas saturation in a porous medium in the presence of gravity: Journal of Colloid and Interface Science, v. 270, p. 388-395.

van den Boogaard, M., and H. Hoetz, 2012, Shallow Gas Play in the Netherlands Takes Off: 74th EAGE Conference and Exhibition incorporating EUROPEC 2012.

Verweij, J., S. Nelskamp, and M. G. Sarmiento, 2013, Timing and distribution of biogenic gas generation in the shallow gas play in the Dutch offshore: 75th EAGE Conference \& Exhibition incorporating SPE EUROPEC 2013.

Widess, M., 1973, How thin is a thin bed?: Geophysics, v. 38, p. 1176-1180.

Yilmaz, Ö., 2001, Seismic data analysis: Processing, inversion, and interpretation of seismic data: Tulsa, Society of exploration geophysicists, $2065 \mathrm{p}$.

Zhao, B., C. W. MacMinn, H. E. Huppert, and R. Juanes, 2014, Capillary pinning and blunting of immiscible gravity currents in porous media: Water Resources Research, v. 50, p. 7067-7081.

Zhao, B., C. W. MacMinn, and R. Juanes, 2016, Wettability control on multiphase flow in patterned microfluidics: Proceedings of the National Academy of Sciences, v. 113, p. 10251-10256.

Ziegler, P., 1992, North Sea rift system: Tectonophysics, v. 208, p. 55-75. 
985 Figure 1. Location maps of the NW Europe (inset) and North Sea with outline of the Permian 986 Basin (grey shade, from Stemmerik et al., 2000), main structural elements, license blocks and 987 position of the 3D volume (study area, red square) and 2D regional seismic profile shown in 988 Figure 2. The study area is located in the Dutch sector and within blocks A and B. It lies at the 989 western flank of the Dutch Central Graben (DCG) and on the Step Graben (SG). CG = Central 990 Graben; MFB = Moray Firth Basin; MNSH = Mid North Sea High; RFH = Ringkøbing Fyn 991 High; VG = Viking Graben (A). Depth structural map of the Top-Chalk (see also Figure 2) 992 with main structural elements at Top Permian (see Figure 2), salt diapirs, and position of the 993 well sites, seismic line and maps shown in the manuscript. Two main fault systems dominate 994 the pre-Zechstein rocks (see Figure 2), westward verging N-S striking normal faults and dextral 995 E-W striking strike-slip faults. The Zechstein rocks produces diapiritic structures observed here 996 as circular diapirs and salt bars. (B).

997 Figure 2. 2D regional seismic section (0-4 s TWT; uninterpreted A; interpreted B) across the 998 Dutch offshore license area with interpretation of main regional horizons and faults (black 999 lines), position of well A15-02 (TD = $2271 \mathrm{~m} \mathrm{MD} \mathrm{[7450} \mathrm{ft} \mathrm{MD])} \mathrm{and} \mathrm{position} \mathrm{of} \mathrm{the} \mathrm{3D} \mathrm{seismic}$ 1000 volume used in this study (see Figure 1 for location). The 3D seismic data is located above the 1001 Step Graben which is here observed as a structural depression where km-scale salt structure 1002 are observed. These salt structures are limited at the top at the Base Chalk. Well A15-02 1003 penetrate the Top Chalk which was encountered at a depth of $2195 \mathrm{~m} \mathrm{MD} \mathrm{(7201} \mathrm{ft).} \mathrm{Top} \mathrm{Chalk}$ 1004 represent the base of the North Sea Group. The pre-Zechstein section includes Namurian, 1005 Dianatian and Devonian rocks with source potential. $\mathrm{SD}=$ salt diapir; VAC $=$ vertical anomaly 1006 cluster; $\mathrm{PV}=$ Pleistocene valleys. $\mathrm{MD}=$ measured depth; Vertical exaggeration $=6.5 \mathrm{x}$.

1007 Figure 3. Arbitrary cross section intersecting well A15-03 and A15-04 (A15-02 is located at 1008 about $500 \mathrm{~m}(1640 \mathrm{ft}$ ) from this cross section) with gamma-ray curves (refer to Figure 1 for 1009 location) (A) and inset showing a close up of the polygonal faults present in the deeper part of 1010 the Upper North Sea Group (B). The section depicts the Upper North Sea Group from the 1011 Middle Miocene Unconformity (MMU), which is expressed in the study area as a long wave 1012 depression simulating the general structure of the Step Graben (see Figure 2), to the seabed. 1013 The group is here divided into 4 units following the stratigraphic subdivision proposed by 1014 Stuart and Huuse, 2012. The interval of interest is represented by the sequence interval S7-S13, 1015 which host all the amplitude anomalies (AAs) observed in the study area and called Anomaly 1016 Interval. The same interval host also numerous iceberg plough-marks (IPs) here observed as 1017 few 10s of meters wide bright soft amplitude anomalies. Pleistocene valleys (PV) produce 1018 vertical region of signal deformation, such as pull-ups and other footprints (PV F-P). Gamma1019 ray curves from well A15-02, -03, and -04 shows, qualitatively, lateral consistency (see Figure 1020 4).

1021 Figure 4. Composite gamma ray logs from well A15-02, -03, and -04 with sequence boundaries 1022 and gas shows (A), and reservoir-seal (R-S) subdivision based on shale volume ( $\left.\mathrm{V}_{\mathrm{SH}}\right)$ derived from gamma-ray log, core data and cuttings from well A15-03 (B). Larionov empirical relation for Cenozoic rock (orange curve; Larionov, 1969) underestimate $\mathrm{V}_{\mathrm{SH}}$ obtained from core data (red square), so $\mathrm{I}_{\mathrm{GR}}$ (red curve) was preferred (50\% of calibrated values still underestimate $\mathrm{V}_{\mathrm{SH}}$; red square circled). $\mathrm{V}_{\mathrm{SH}}=0.5$ and $10 \mathrm{mD}$ are standard value to separate reservoirs and seals for gas bearing sediments (Jahn et al., 2008), but this threshold overestimates the number of reservoir and it includes here lithologies with low permeability (K) (e.g. see at Core $3, \mathrm{~V}_{\mathrm{SH}} 0.5$ and $<10 \mathrm{mD})$. Lower $(0.15)$ and upper $(0.38)$ boundary for $\mathrm{V}_{\mathrm{SH}}$ were defined based on sand1030 rich package at top of $\mathrm{S} 12$ and sandy siltstone at Core 11 with permeability $>100 \mathrm{mD}$, 
respectively. The average of these values $\left(\mathrm{V}_{\mathrm{SH}}=0.26\right)$ was finally adopted to separate reservoir and seal intervals. This values shows good match with reservoir interval and gas shows (dark green square = gas shows $@$ A15-02, light green square = projected gas shows) $(\mathrm{B}) . \mathrm{MD}=$ measured depth.

Figure 5. Representative 2D seismic section depicting the Middle Miocene Unconformity (MMU) and the lower section of the Upper North Sea Group (A, refer to Figure 1 and 5BC for line location) and amplitude map and chaos map along sequence boundary S9-S10 (refer to Figure 1and Figure 5A for location). Contourite sand bars characterised by negative amplitude response can be observed within and at the top of S5. Two clear sets of truncated reflections representing the onset of forced regression are observed at the top of S6 and at S7 (inset, A). Amplitude map along S9-S10 (red horizon; Figure 5A) showing amplitude anomalies (AAs), iceberg plough marks (IPs) and footprint of Pleistocene valleys (PV F-P) (B). Chaos attribute map along S9-S10 (red horizon; Figure 5A). Amplitude anomalies produce footprint that can be observed as a region of apparent low chaos (AA F-P) within a region of chaotic facies. Low chaos facies can be observed in the western portion of the map. PFS = polygonal fault system.

Figure 6. Representative cross sections depicting the seismic expression of the encountered VACs in the study area (VAC1, A; VAC2, B; VAC3, C; VAC4, D; refer to Figure 1 for location). All the VACs are composed of 5-7 amplitude anomalies (AAs) showing vertical overlap and generally increasing size with depth. At true-scale, the VACs show tabular geometry (true-scale insets). The AAs are characterised by trough-peak loops and shows continuous character respect to the surrounding reflectivity (B, inset). VACs are affected by footprints and pull-ups related to transmission artefacts caused by the presence of Pleistocene glacial valleys (PV F-P) in the near-seabed. Amplitude map along S10-S11 showing VAC 1 and 2 (E) and amplitude profile along XLINE 1824 (F). The VACs shows high amplitude anomalies but VAC2 exhibits sharp amplitude cut-off with respect to VAC1. VAC1 shows also amplitude attenuation (Att.) produced by shallow amplitude anomalies. Iceberg plough marks (IPs) are also observed. Some of the amplitude anomalies (AAs) and importantly VAC2 seems confined by these features.

Figure 7. Base Chalk (A), Top-Sequence S11 (B) depth structural maps with superimposed minimum amplitude map, and uninterpreted (C) and interpreted (D) cross section depicting the geometrical correlation of the salt structures with VAC-1 and AAs. The minimum amplitude map was calculated extracting the minimum seismic amplitude value within a window of 400 ms centred along Top 11 (C). The Base Chalk is punctured by circular and elongated salt diapirs characterised by heights of 250-500 m (820-1640 ft). Three VACs and some of the amplitude anomalies (AAs) are clearly located above prominent Zechstein structures. No VACs or AAs are found in the easternmost portion of the study area although prominent structural salt features are observed (A). The top-Sequence S11 is dominated by the N-S sagging related to the structural setting of the Step Graben. Also a prominent foot-print of the shallower Pleistocene valley is observed (PV F-P). A gentle doming at the centre of the study area plunging gently to NE is also observed. VACs and AAs seems unrelated to the geometry of top-Sequence S11 although VAC1 is located nearly along the axis of the doming. The cross section shows VAC-1 located above a salt structure deforming the Base Chalk. A minor group of AAs are also observed above a smaller salt diapir (SD).

Figure 8. Seismic cross sections (A-B) and amplitude maps (C-D) depicting the main acoustic features of VAC1. VAC1 composed of 7 seismic amplitude anomalies (AAs) showing vertical overlap and close perimeter. AA2 and 3 are composed of two separated anomalies each (see Figure $10 \mathrm{~A}$ ). Footprints produced by shallow Pleistocene valleys (PV F-P) propagate downward into the VAC producing disturbed regions observed in both cross section and in 
map view. The lower AAs shows transmission artefacts produced also by the overlying anomalies. These include attenuation and push down (Att. \& PD). Iceberg plough marks (IPs) are observed in the sections hosting the central AAs. The shape of VAC2 seems controlled by IPs. Lithology related acoustic changes are observed but they are uncorrelated with the shape of the AAs.

Figure 9. Depth map of Top S8 (A) and Intra S11 (B) with margin of AA7 (A) and AA5 (B), respectively. The iso-depth lines are spaced $2 \mathrm{~m}(6.5 \mathrm{ft})$. The depth maps show a maximum relief of $8 \mathrm{~m}(26.25 \mathrm{ft})$ between the centres and the perimeters of the anomalies. Divergent patterns between perimeter of AAs and iso-depth lines is indicated in two representative regions with red arrows; line crossing between iso-depth lines and amplitude anomalies is highlighted in four representative regions by red circles. These features indicate a lack of conformation to structure. PV=Pleistocene valleys (dashed line=approximate footprint extent); $\mathrm{PD}=$ push-down effect.

Figure 10. Analysis of the margins of the amplitude anomalies (AA) of VAC1. Outline of the AAs of VAC1 and location of the centroids (A). The AAs of VAC1 are characterised by a gross similar planform shape (B). AA2 to AA7 exhibit a systematic increase of area with depth (C). The centroids are aligned along a linear pattern (orange and red crosses), or distributed into two groups: centroid group 1 and 2 (CG1 and CG2) (D). Conceptual evolution of two AAs: at $\mathrm{t}=1$ two initially separated AAs give two centroids located at their centres (red crosses), at $\mathrm{t}=2$ the AAs grow, at $\mathrm{t}=3$ the AAs coalesce together and form a single "eight-shaped" anomaly giving one single centroid (blue cross; $t=3$ ) (E).

Figure 11. Composite showing the calibration of VAC1 including a seismic cross section across VAC1, synthetic, wireline logs, petrophysical analyses and sedimentary structure of the reservoir intervals encountered in Core 2. VAC1 depicted on cross section and visualised as wiggle display with positive reflection coefficient $(\mathrm{RC}+)$ represented as a peak. Position of the synthetic from well A15-03. Projection of seismic amplitude anomalies and gas shows show a good match (A). Synthetic seismogram and seismic trace at well location (B). Compressional velocity $(\mathrm{Vp})$ and blocked velocity used to derive the synthetic shows good calibration $(\mathrm{C})$. Crossplot of neutron porosity (NP) and scaled density ( $\rho$, see method section) reveals the presence of potential sub-seismic gas bearing reservoir intervals (see text) (D). Gamma-ray index and Larionov empirical relation for shale content calibrated with shale volume extracted from core data. The gamma-ray index underestimate shale content (see text and Figure 4). Reservoir-seal intervals derived from shale threshold at $\mathrm{V}_{\mathrm{SH}}=0.26$. AA5, 6,7 are hosted by multiple reservoirs. Neutron porosity overestimate porosity observed on core data. average porosity for the reservoir intervals decrease with depth (E). sedimentary structure interpreted from core 2. Siltstone reservoirs, 2 and 3, defined by using $\mathrm{V}_{\mathrm{SH}}$ are characterised by ripple structures. Gas show extend over the defined reservoir intervals. SRD = seismic reflection datum; MD = measured depth;

Figure 12. Core pore throat radii vs. buoyancy cross-plot used to assess the trapping, or buoyancy, dynamic state of the observed amplitude anomalies (AAs) of VAC1 (A). The lengths of the AAs here represent the minimum and maximum axes extent (in $\mathrm{km}$ ) for each AAs. The layer slope represents the maximum dip of each half-axes from the centre to the margin of the relative AA. The capillary entry pressure, Pce, was calculated assuming an interfacial tension for water and gas of $60 \mathrm{mN} / \mathrm{m}$ (see text). Buoyant and trapped fields were defined by assuming ideal reservoir properties (homogenous, free pore space). This may underestimate trapping (overestimate buoyancy). The thick dotted line defines the threshold below which the AAs result trapped within a reservoir interval characterised by hydraulic property in line to those observed at core 2 (this case is highlighted by the yellow shade). For deeper reservoirs (>871.5 
$1127 \mathrm{~m}[2859 \mathrm{ft}]$ ), the threshold, at which the gas (related to the AAs) became buoyant, is higher 1128 and here plotted with the thick dashed line (this case is highlighted by the orange shade) (A). 1129 Fingering pattern from laboratory experiments (modified from Zhao et al., 2016). Position of 1130 the centroids (red crosses) are located nearly at the injection points (white circles) (B). Semi1131 transparent partial 3-D visualisation of bright negative amplitudes of VAC1 (cutting plane at 1132 centroid group CG2, refer to Figure 10D for CG2 location). Position of the centroids indicate 1133 a vertical pathway, or conduit, which represent the region where (1) the cross-stratal migration, 1134 and (2) the injection of gas into the reservoir layers take place. 
1136 Figure 1.

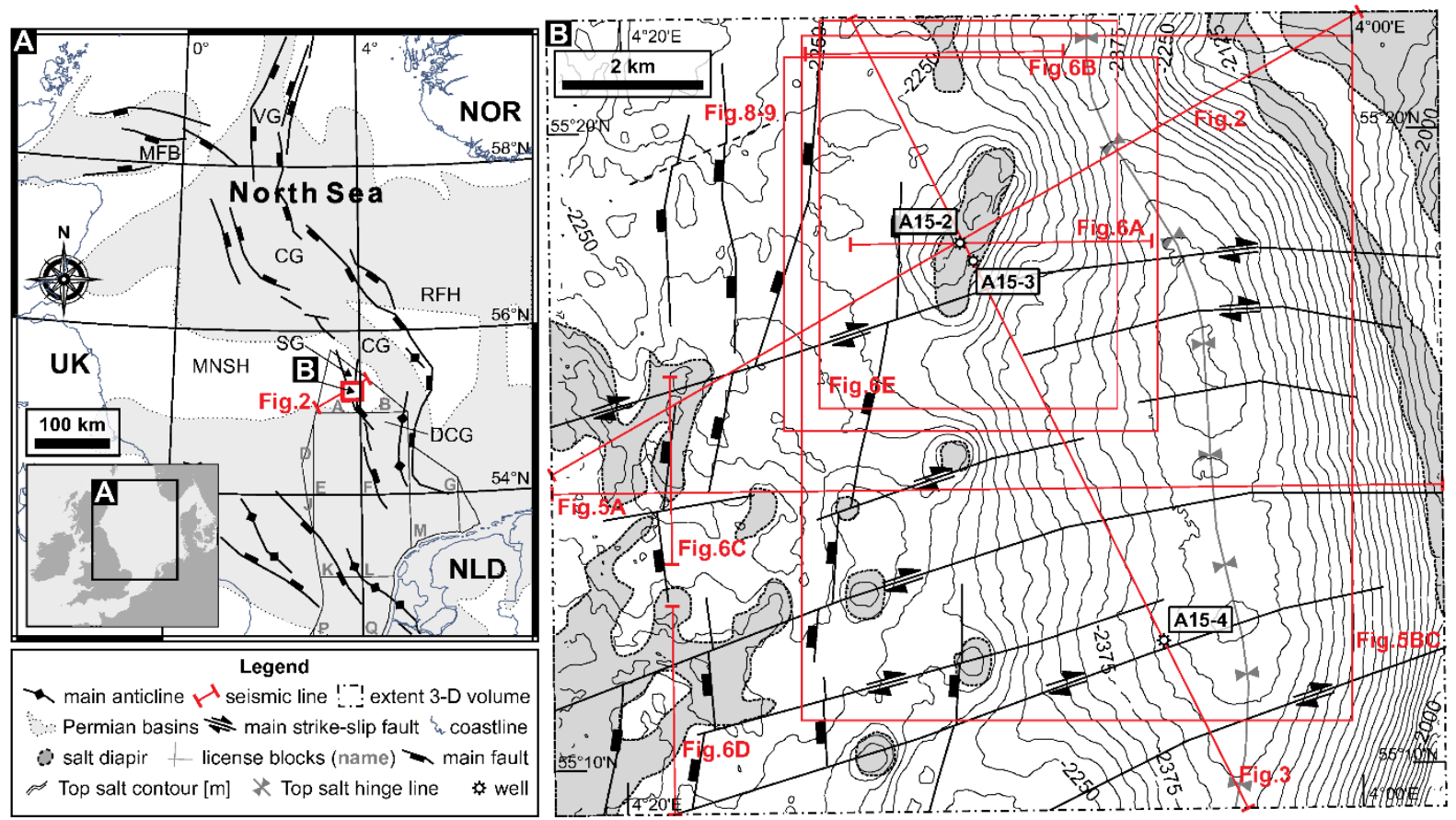


1139 Figure 2.

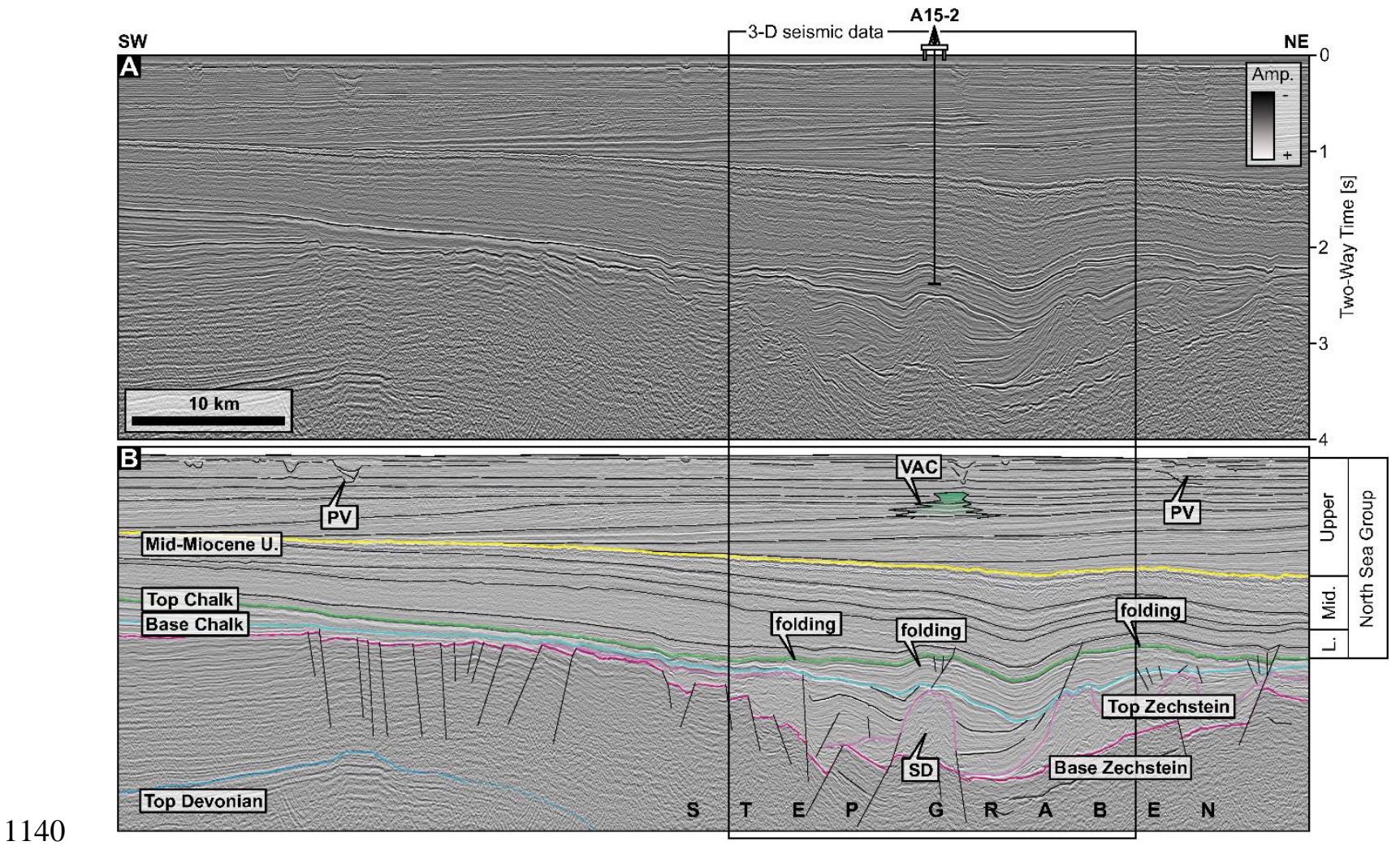

1141 
1142 Figure 3.

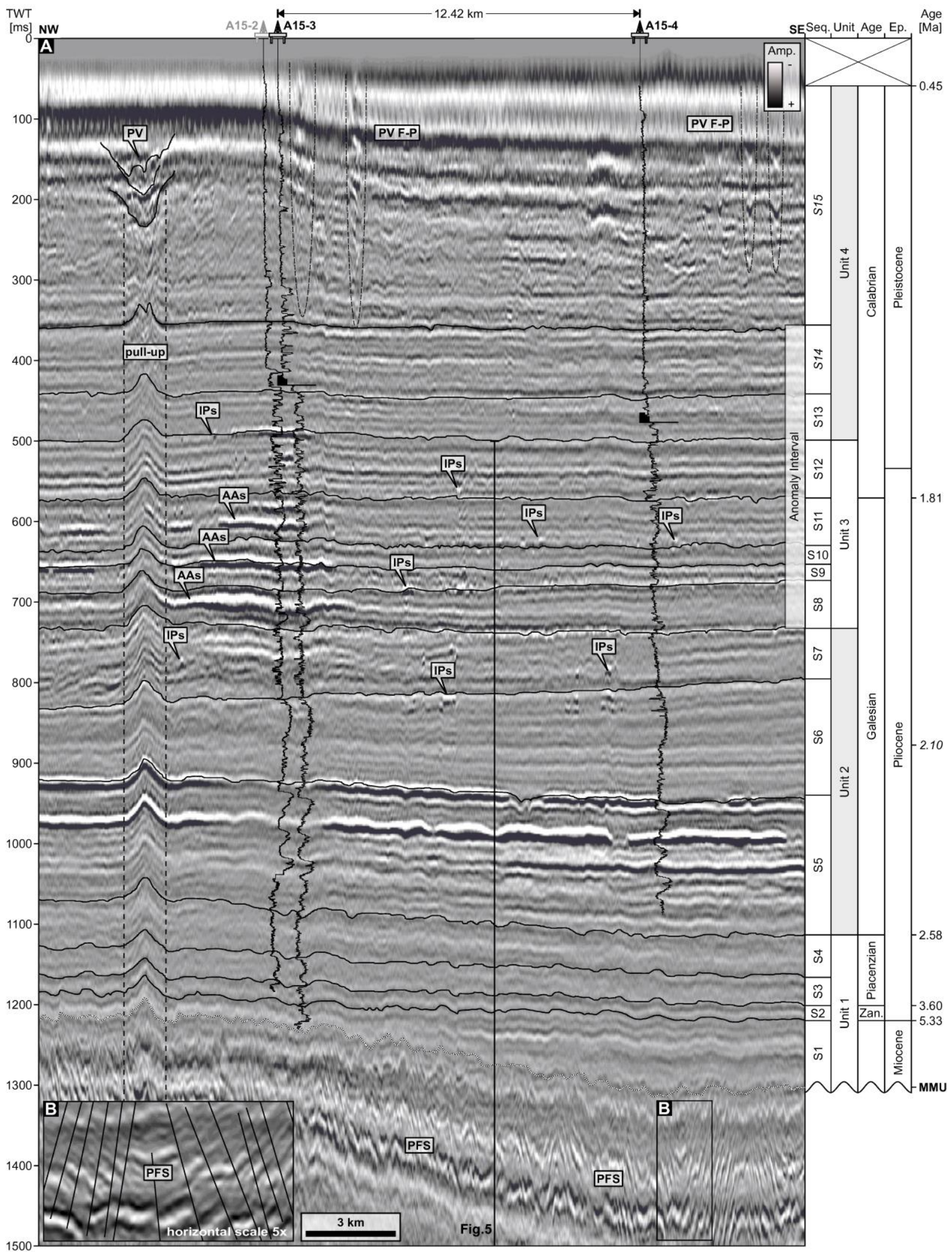


1145 Figure 4.
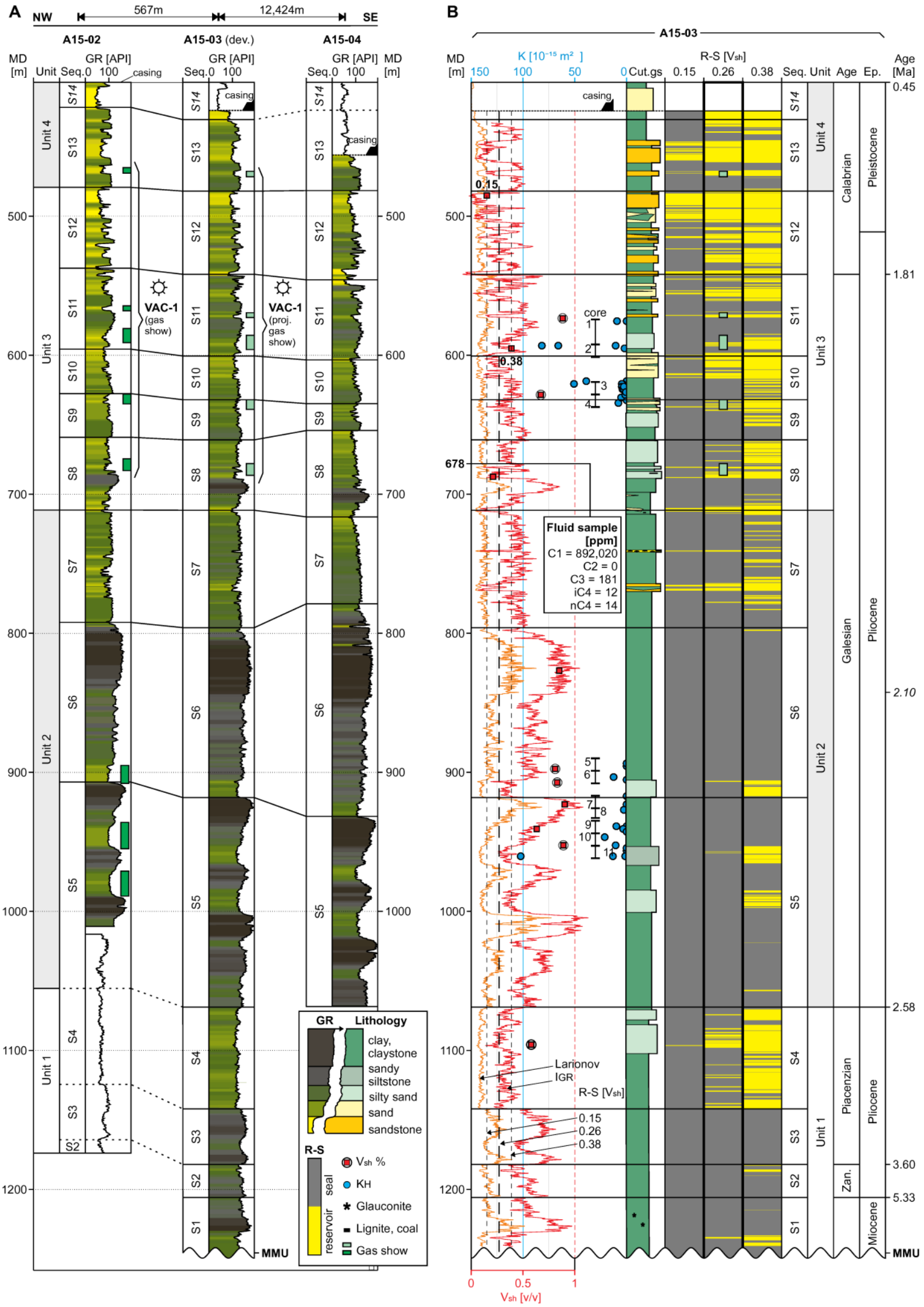
1148 Figure 5.

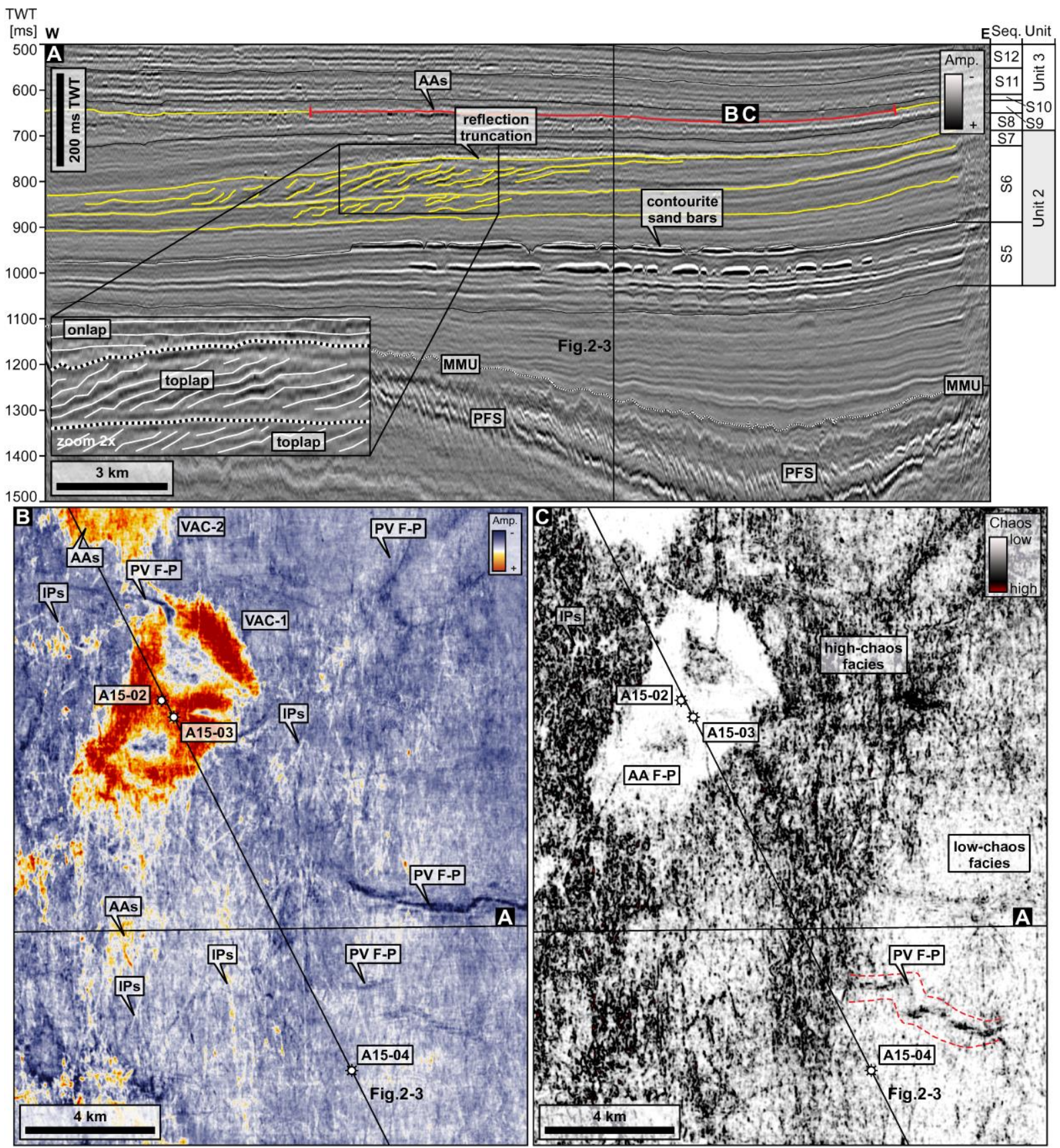


1151 Figure 6.

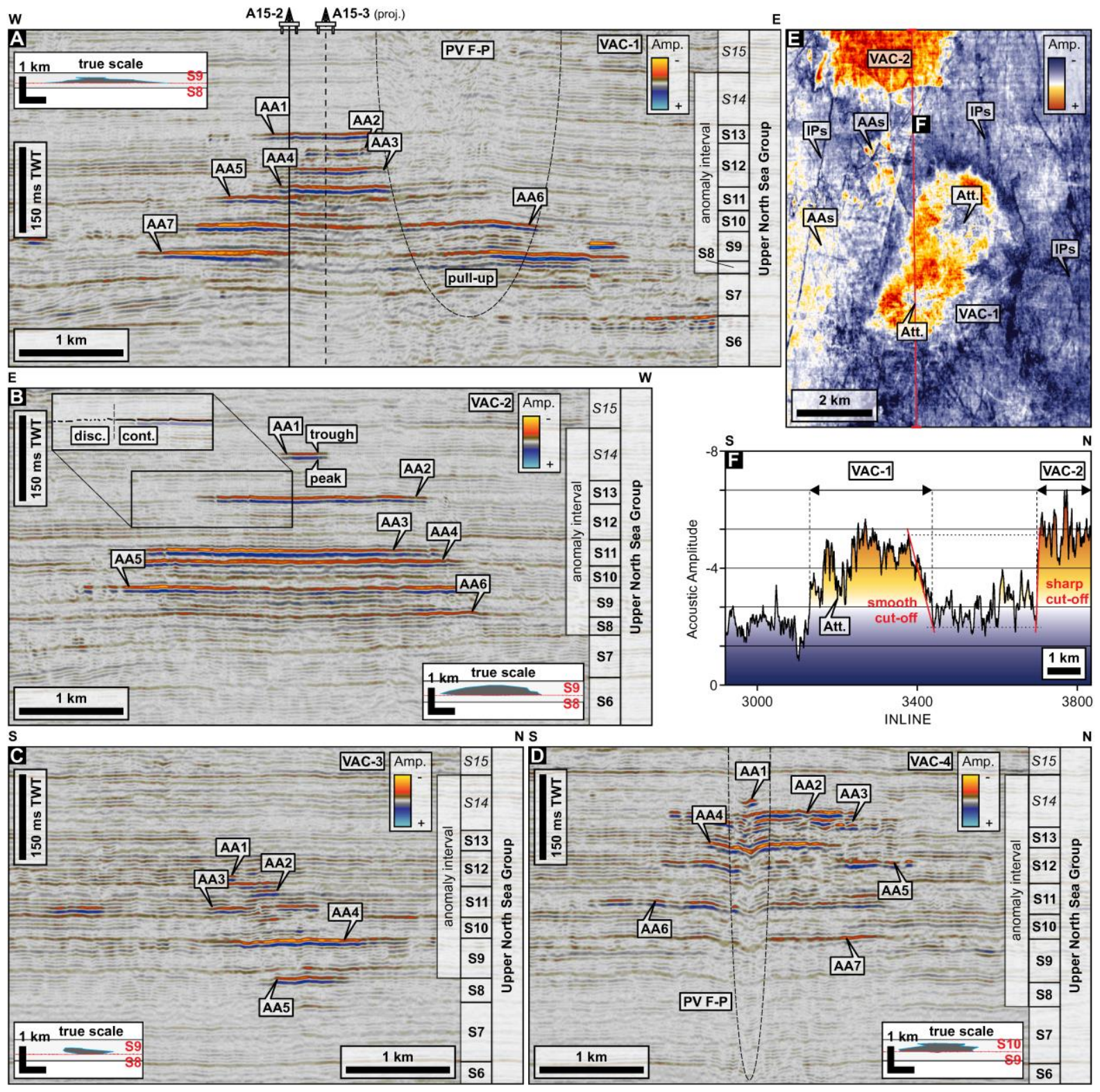


1154 Figure 7.
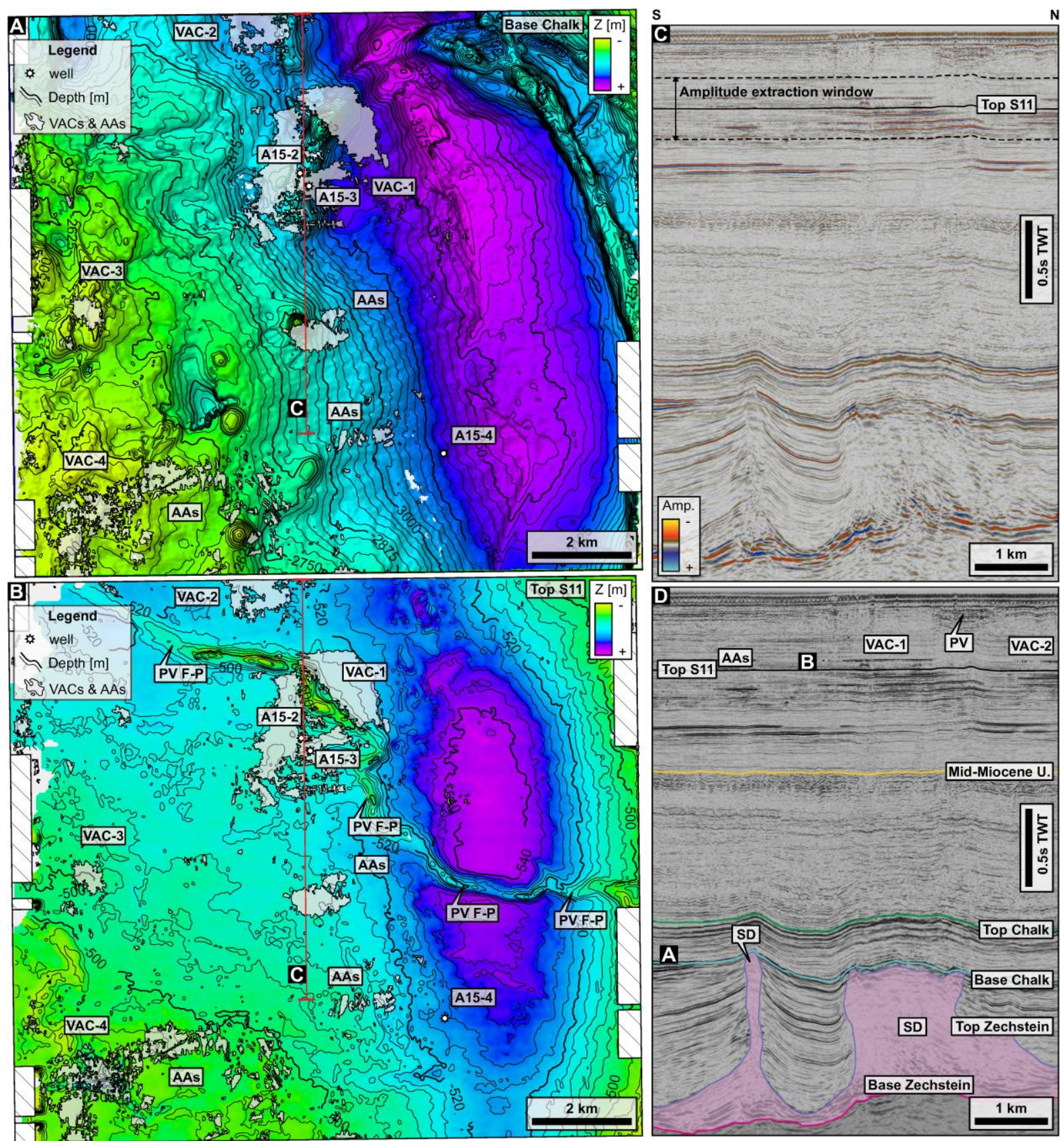
Figure 8.
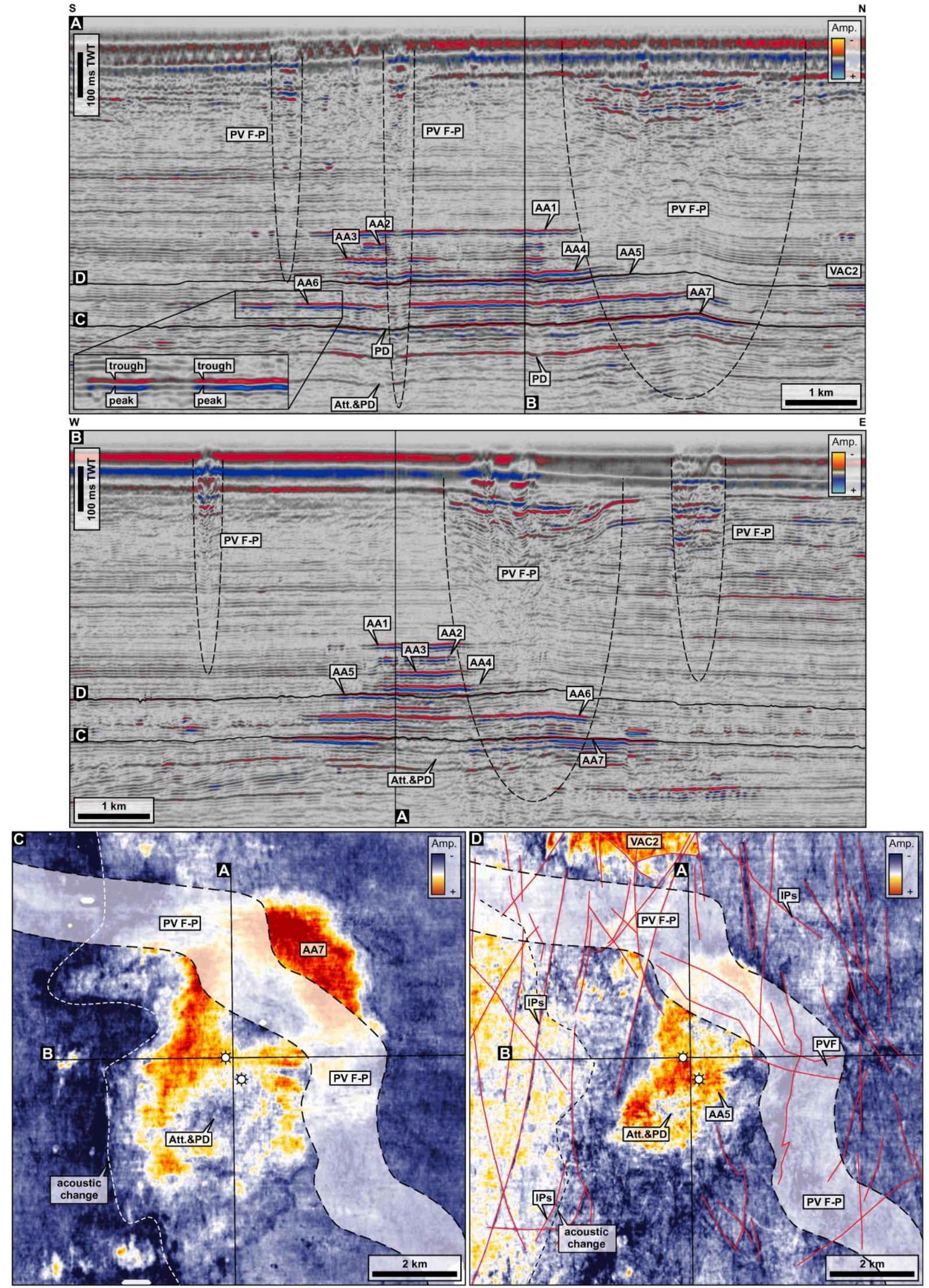
1160 Figure 9.

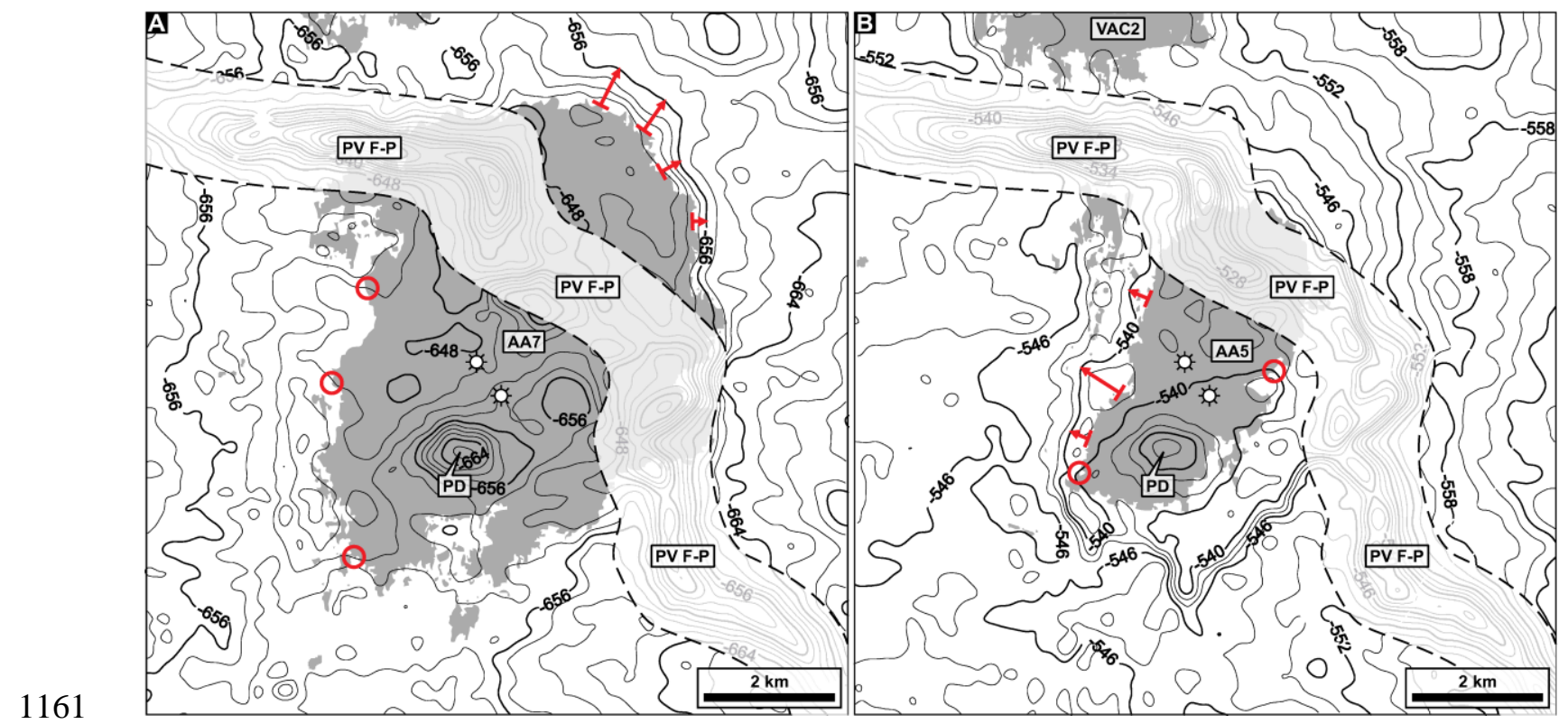


1163 Figure 10.

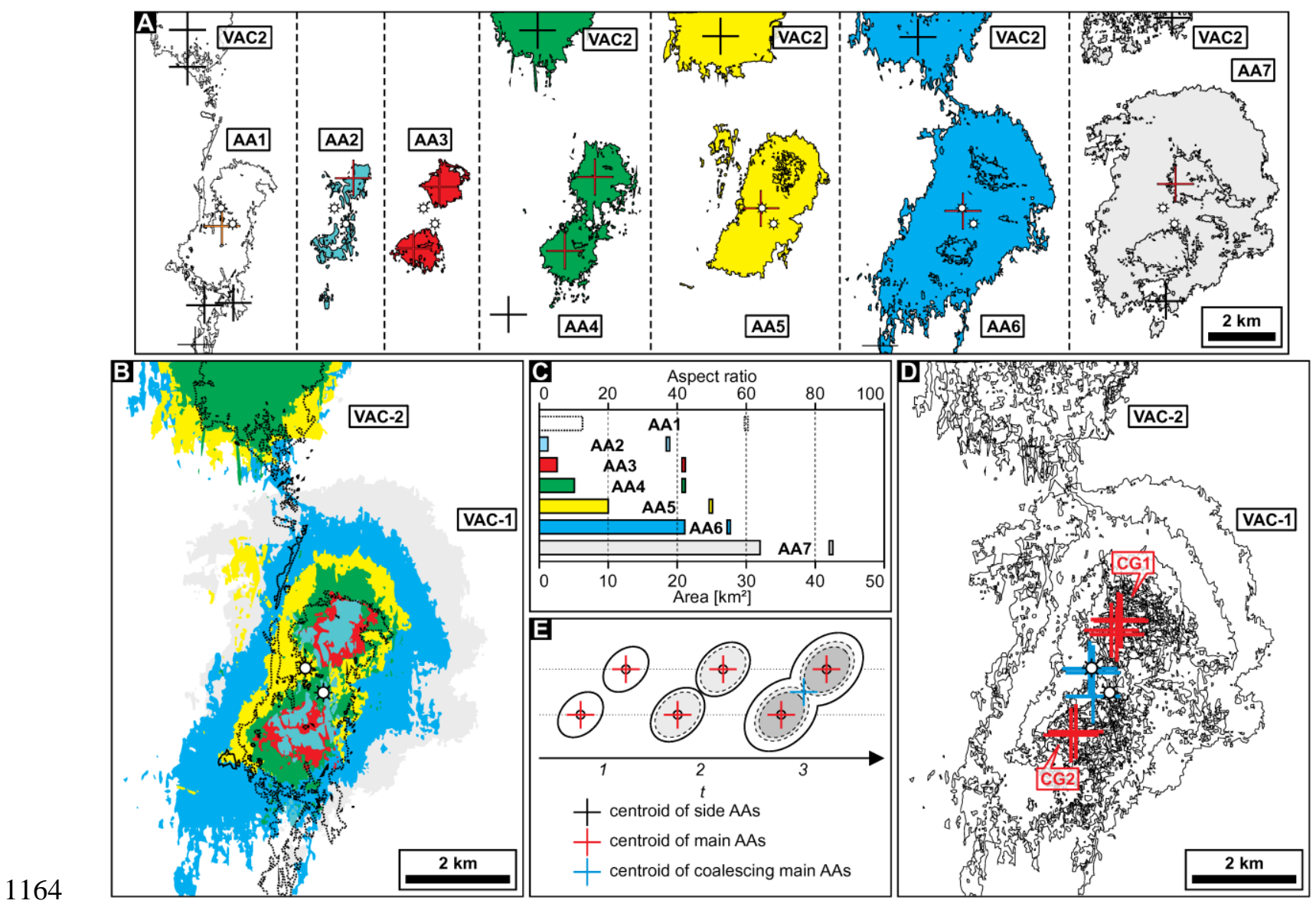


1166 Figure 11
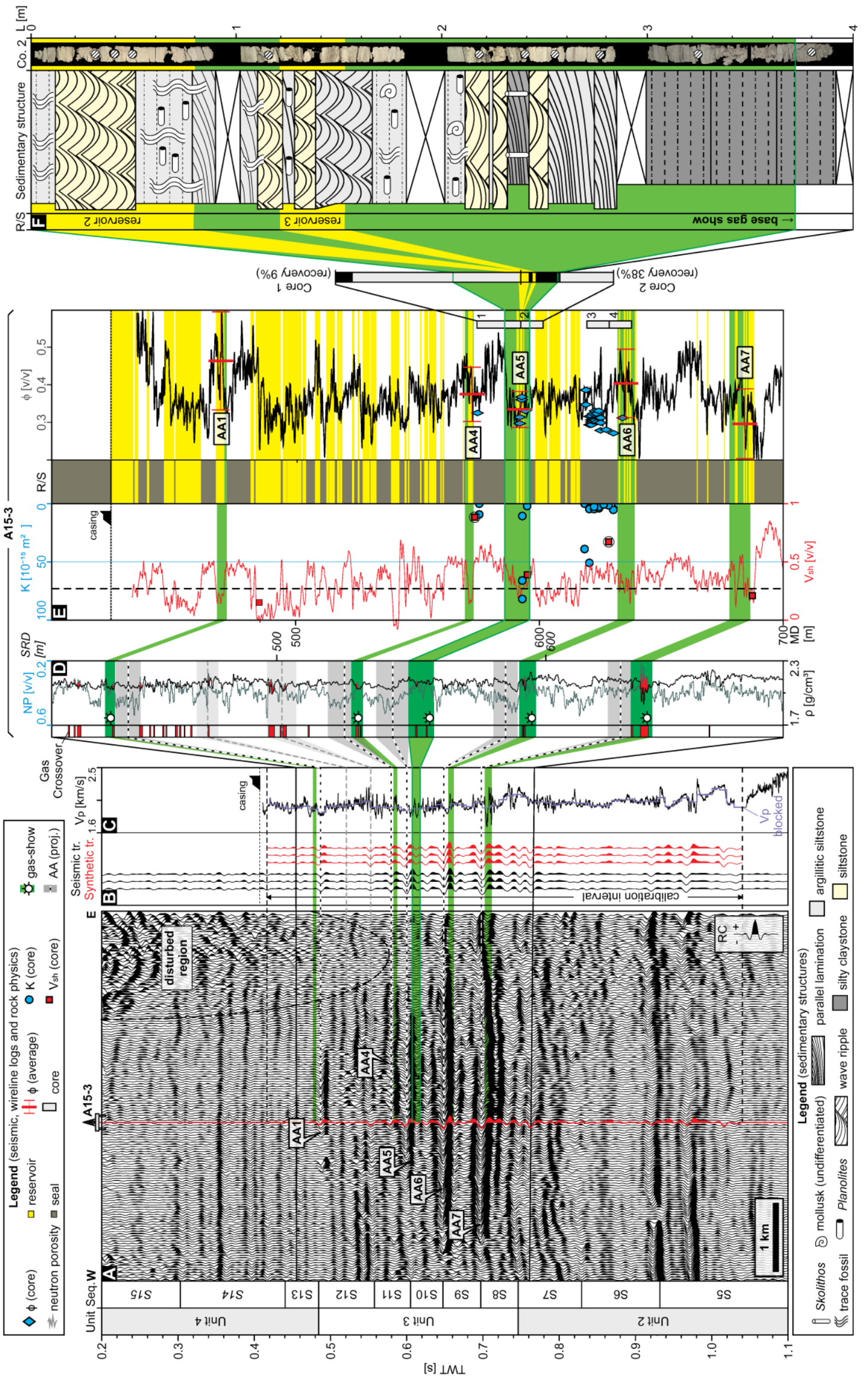

1167 
1168 Figure 12.
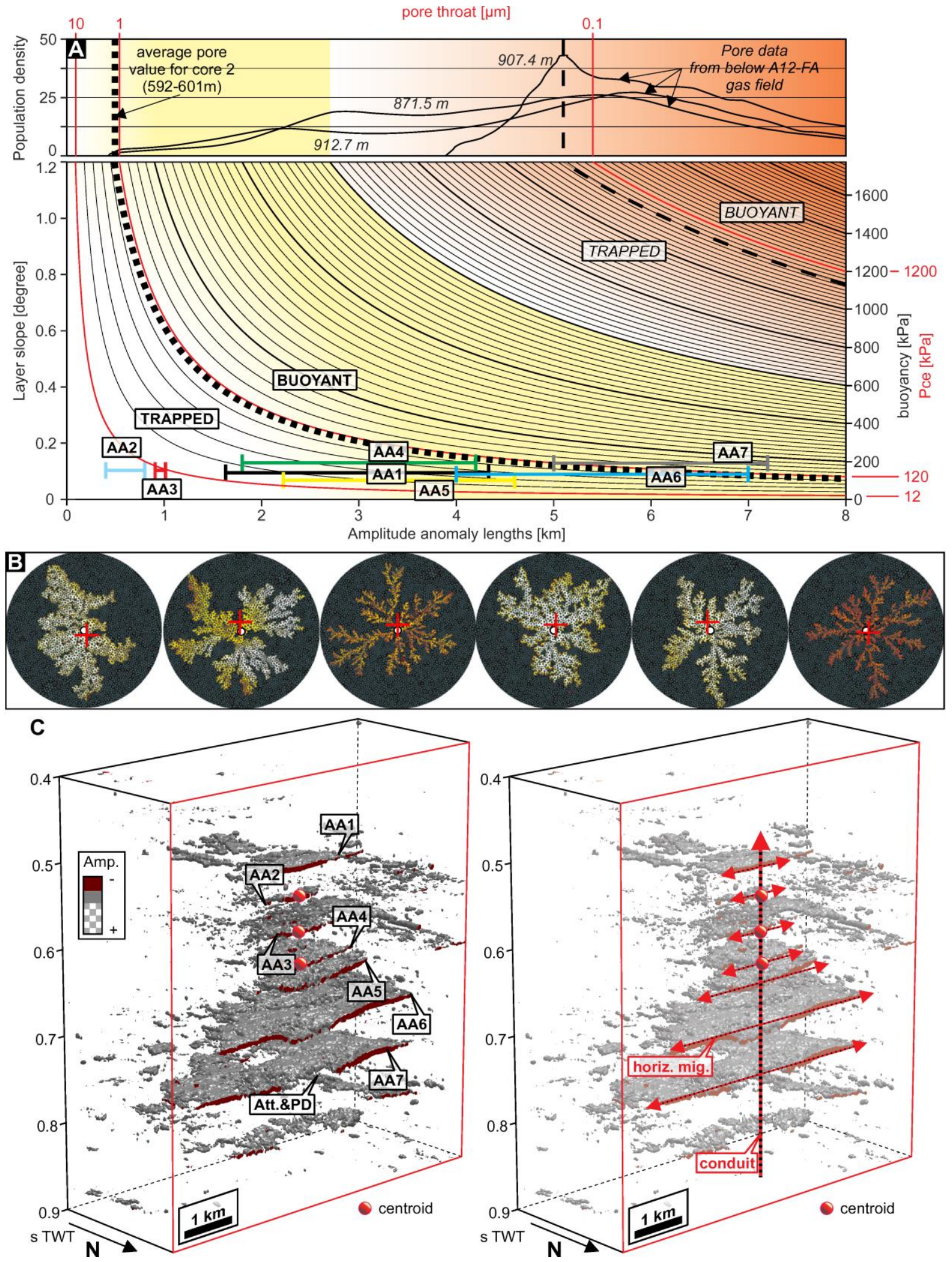
